\title{
Common Origins of Hippocampal Ivy and Nitric Oxide Synthase Expressing Neurogliaform Cells
}

\author{
Ludovic Tricoire, ${ }^{1}$ Kenneth A. Pelkey, ${ }^{1}$ Michael I. Daw, ${ }^{1}$ Vitor H. Sousa, ${ }^{2}$ Goichi Miyoshi, ${ }^{2}$ Brian Jeffries, ${ }^{1}$ Bruno Cauli, ${ }^{3}$ \\ Gord Fishell, ${ }^{2}$ and Chris J. McBain ${ }^{1}$ \\ ${ }^{1}$ Laboratory of Cellular and Synaptic Neurophysiology, Eunice Kennedy-Shriver National Institute of Child Health and Human Development, National \\ Institutes of Health, Bethesda, Maryland 20892, ${ }^{2}$ Smilow Neuroscience Program and the Department of Cell Biology, New York University, New York, \\ New York 10016, and ${ }^{3}$ Laboratoire de Neurobiologie des Processus Adaptatifs, Université Pierre et Marie Curie, CNRS UMR 7102,75005 Paris, France
}

GABAergic interneurons critically regulate cortical computation through exquisite spatiotemporal control over excitatory networks. Precision of this inhibitory control requires a remarkable diversity within interneuron populations that is largely specified during embryogenesis. Although interneurons expressing the neuronal isoform of nitric oxide synthase (nNOS) constitute the largest hippocampal interneuron cohort their origin and specification remain unknown. Thus, as neurogliaform cells (NGC) and Ivy cells (IvC) represent the main nNOS ${ }^{+}$interneurons, we investigated their developmental origins. Although considered distinct interneuron subtypes, NGCs and IvCs exhibited similar neurochemical and electrophysiological signatures, including NPY expression and late spiking. Moreover, lineage analyses, including loss-of-function experiments and inducible fate-mapping, indicated that $\mathrm{nNOS}^{+}$IvCs and NGCs are both derived from medial ganglionic eminence (MGE) progenitors under control of the transcription factor Nkx2-1. Surprisingly, a subset of NGCs lacking nNOS arises from caudal ganglionic eminence (CGE) progenitors. Thus, while nNOS ${ }^{+} \mathrm{NGCs}$ and IvCs arise from MGE progenitors, a CGE origin distinguishes a discrete population of nNOS ${ }^{-}$NGCs.

\section{Introduction}

Cortical circuit processing critically relies on the ability of a relatively small number of GABAergic inhibitory interneurons to temporally and spatially coordinate information transfer among large numbers of glutamatergic principal cells (Somogyi and Klausberger, 2005). Disruption of this excitation-inhibition dynamic is a precipitating factor in several neurological disorders (Levitt et al., 2004; Cossart et al., 2005; Lewis et al., 2005), and developmental studies indicate that several genes associated with such disorders are expressed in interneurons during embryogenesis (Batista-Brito et al., 2008). Therefore, interneuron misspecification early in development may underlie pathological alterations of mature cortical networks (BatistaBrito and Fishell, 2009). However, the remarkable diversity of

\footnotetext{
Received 0ct. 7, 2009; revised Nov. 30, 2009; accepted Dec. 24, 2009.

This work was supported by a National Institute of Child Health and Human Development (NICHD) intramural award to C.J.M. Research in Fishell laboratory is supported by National Institutes of Health (NIH) Grants R01NS039007 and R01MH07679 and by generous support from the Simons Foundation and New York State through their New York State Stem Cell Science initiative. B.C. is supported by a Human Frontier Science Program grant (RGY0070/2007) and by a Centre National de la Recherche Scientifique (CNRS) grant ("Nitrex"). L.T. is an NIH Visiting Fellow and a NIH/CNRS ECTA Fellow. G.M. was supported by a grant from the Japan Society for the Promotion of Science. We thank Xiaoging Yuan, Daniel Abebe, and Helene Geoffroy (Ecole Superieure de Physique et Chimie Industrielles de Paris, France) for expert technical assistance. Microscopy imaging was performed at the Microscopy and Imaging Core (NICHD, NIH) with the assistance of Dr. Vincent Schram. We thank Dr. Betty A. Eipper for supplying us with the NPY antibody and Dr. Stewart A. Anderson for providing us the Nkx2-1BAC-Cre driver line.

Correspondence should be addressed to Chris J. McBain, Laboratory of Cellular and Synaptic Neurophysiology, National Institute of Child Health and Human Development, Porter Neuroscience Research Center, 35 Lincoln Drive, MSC 3715, Bethesda, MD 20892-3715. E-mail: mcbainc@mail.nih.gov.

D0I:10.1523/JNEUROSCI.5123-09.2010

Copyright $\odot 2010$ the authors $\quad 0270-6474 / 10 / 302165-12 \$ 15.00 / 0$
}

interneurons has confounded our understanding of their precise roles in controlling network computation.

Recently, developmental criteria have been used to explore the functional diversity of interneurons (Wichterle et al., 2001; Nery et al., 2002; Butt et al., 2005, 2008; Miyoshi et al., 2007; Sousa et al., 2009). Indeed, the ultimate fate of an interneuron, the subgroup to which it belongs, and thus its role in the mature cortical network, is in part dictated by early specification during embryogenesis (Butt et al., 2005; Miyoshi et al., 2007; Batista-Brito and Fishell, 2009). Neocortical and hippocampal interneurons originate mainly from the medial and the caudal ganglionic eminences (MGE and CGE, respectively) in the ventral telencephalon (Anderson et al., 1999; Lavdas et al., 1999; Sussel et al., 1999; Pleasure et al., 2000; Wichterle et al., 2001; Nery et al., 2002; Butt et al., 2005; Fogarty et al., 2007). MGE-derived interneurons ultimately give rise to parvalbumin (PV)- and somatostatin (SOM)-expressing interneuron cohorts, whereas calretinin (CR)- and vasoactive intestinal peptide (VIP)-expressing interneurons arise from the CGE (Xu et al., 2004; Butt et al., 2005; Fogarty et al., 2007; Miyoshi et al., 2007). Curiously, in the hippocampus, the neuronal isoform of nitric oxide synthase (nNOS) is expressed in an interneuron subpopulation that does not overlap with PV or SOM interneurons (Fuentealba et al., 2008b) and also largely segregates from CR interneurons (Jinno and Kosaka, 2002), leaving the developmental origin of nNOS interneurons in question. nNOS strongly colocalizes with neuropeptide $\mathrm{Y}$ in both Ivy cells (IvCs) (Fuentealba et al., 2008b; Szabadics and Soltesz, 2009) and a subset of neurogliaform cells (NGCs) (Price et al., 2005). Based on laminar positioning, IvCs and NGCs are considered distinct interneuron subtypes with unique functional roles 
during hippocampal rhythmic activity (Fuentealba et al., 2008b). However, the similar electrophysiological, anatomical, and molecular properties of IvCs and NGCs suggest that they may belong to the same interneuron family (Szabadics and Soltesz, 2009). Interestingly, NPY containing interneurons have dual origins arising from both the MGE and CGE (Butt et al., 2005; Fogarty et al., 2007), raising the intriguing possibility that $\mathrm{nNOS}^{+} / \mathrm{NPY}^{+}$ NGCs and IvCs can be parsed based on lineage. Here we used a multiparametric approach combining genetic, molecular, immunohistochemical, and electrophysiological analyses to directly compare and contrast the developmental origins of nNOS hippocampal interneurons with particular emphasis on IvCs and NGCs.

\section{Materials and Methods}

Animals. All experiments were conducted in accordance with animal protocols approved by the National Institutes of Health.

Double-heterozygote $\mathrm{Olig}^{\mathrm{CreER/+}}:{\mathrm{Z} / E G^{+/-}}$(Novak et al., 2000; Takebayashi et al., 2002) and double-homozygous Mash1BAC CreER/CreER/ RCE:LoxP $P^{+/+}$(Miyoshi et al., 2010) male mice were crossed with 6- to 8 -week-old wild-type Swiss Webster females (Taconic) for litter production. Pregnant mice received tamoxifen [2 $\mathrm{mg}$ on embryonic day 9.5 (E9.5) and E10.5, $3 \mathrm{mg}$ on E11.5 and E12.5, $4 \mathrm{mg}$ on E13.5 and E14.5, and $3 \mathrm{mg}$ on E16.5; Sigma-Aldrich] dissolved in corn oil $(20 \mathrm{mg} / \mathrm{ml}$; SigmaAldrich) between 1:00 and 3:00 P.M. by oral gavage with a siliconprotected needle (Fine Science Tools).

Genotyping was done by PCR with the following primers: Olig2 ${ }^{\mathrm{CreER}}$, forward, TCGAGAGCTTAGATCATCC; reverse, CACCGCCGCCCAGTTTGTCC; mutant reverse, GGACAGAAGCATTTTCCAGG (wild type: $247 \mathrm{bp}$, mutant:172 bp); Z/EG, forward, ACACCCTGGTGAACCGCATCGAG, reverse, GCGCTTCTCGTTGGGGTCTTTGC (296 bp); Mash1BAC-CreER, forward, AACTTTCCTCCGGGGCTCGTTTC, reverse, TCCACTCTCCATCTTGCCAGAG, mutant reverse, CGCCTGGCGATCCCTGAACATG (wild type: $169 \mathrm{bp}$, mutant: $247 \mathrm{bp}$ ); RCE: LoxP, forward, CCCAAAGTCGCTCTGAGTTGTTATC, reverse, GAAGGAGCGGGAGAAATGGATATG, mutant reverse, CCAGGCGGGCCATTTACCGTAAG (wild type: 550 bp, mutant: 350 bp); Nkx2-1Cre, forward, AAGGCGGACTCGGTCCACTCCG, reverse, TCCTCCAGGGGACTCAAGATG, mutant reverse: TCGGATCCGCCGCATAACCAG (wild type: $220 \mathrm{bp}$, mutant: $550 \mathrm{bp}$ ). Alternatively, Z/EG allele screening was performed using LacZ staining with fluorescein di- $\beta$-D-galactopyranoside (Anaspec). $\mathrm{Nkx} 2-1^{-}$and $\mathrm{Nkx} 2-1^{\mathrm{flx}}$ alleles were genotyped using the primer as described by Butt et al. (2008). NPY-hrGFP (Jackson Laboratory) mice were genotyped as described in van den Pol et al. (2009). Alternatively, postnatal day (P)0-P2 NPY-hrGFP and Nkx2-1BAC-Cre/ RCE:LoxP pups were examined under blue light illumination for screening cerebral GFP fluorescence. NPY-tau-GFP (Jackson Laboratory) mice were genotyped using the same primers as used for the ZEG mouse.

Immunofluorescence. Three- to four-week-old mice were perfused transcardially using a $0.1 \mathrm{M}$ PBS solution containing $4 \%$ paraformaldehyde followed by 1 or 3 h of postfixation. Brains were cryoprotected using $20-30 \%$ sucrose/PBS solution, sliced to $40 \mu \mathrm{m}$ thickness using a freezing microtome, and kept at $4^{\circ} \mathrm{C}$ for up to 3 weeks until used. Free-floating sections were blocked for $2 \mathrm{~h}$ at room temperature in a PBS/0.5\% Triton $\mathrm{X}-100 / 1 \% \mathrm{BSA} / 10 \%$ normal goat serum (NGS) solution before being incubated overnight at $4^{\circ} \mathrm{C}$ with primary antibodies diluted in a $\mathrm{PBS} / 1 \%$ BSA $/ 1 \%$ NGS solution (BG-PBS). Slices were washed with BG-PBS supplemented with $0.5 \%$ Triton X-100 before being incubated for $1 \mathrm{~h}$ at room temperature with secondary antibodies diluted in BG-PBS. Nuclear counterstaining was performed with $100 \mathrm{ng} / \mathrm{ml}$ DAPI (4',6-diamidino-2-phenylindole; Invitrogen) solution in PBS for 20 min. After extensive washing in PBS, slices were mounted on gelatin-coated slides in Vectashield (Vector Laboratories). Antibodies were used in the following concentrations: mouse anti-PV (1:1000; Sigma-Aldrich), rabbit anti-PV (1:1000; Swant), rabbit anti-SOM (1:500; Dako), rabbit anti-NPY (1:500; Immunostar), rabbit anti-NPY [1:1000; a generous gift from Betty Eipper, University of Connecticut Health Center, Farmington, CT; code JH3 (Milgram et al., 1996)], rabbit anti-VIP (1:500; Immunostar), rabbit anti-CR (1:1000; Millipore), rabbit anti-nNOS (1:1000, Millipore), mouse anti-nNOS (1:1000, Sigma-Aldrich), mouse anti-Coup TFII (1: 500; Perseus Proteomics), chicken anti-GFP (1:2000; Aves Laboratories), goat anti-chicken alexafluor488 (1:500; Invitrogen), $\mathrm{F}(\mathrm{ab}) 2$ fragment of goat anti-rabbit alexafluor555 (1:500; Invitrogen), and goat anti-mouse alexafluor633 (1:500; Invitrogen). Fluorescent images were captured using a Retiga 4000R cooled CCD camera (Qimaging) or using a Live Duo scan confocal system (Zeiss).

In situ hybridization. Postnatal P15-P17 brains were fixed by transcardial perfusion followed by $4 \mathrm{~h}$ to overnight postfixation with $4 \% \mathrm{PFA} /$ PBS solution at $4^{\circ} \mathrm{C}$. Brain tissue was then rinsed with PBS, cryoprotected using $30 \%$ sucrose/PBS solution overnight at $4^{\circ} \mathrm{C}$, embedded in Tissue Tek, frozen on dry ice, and sectioned at $12 \mu \mathrm{m}$. Section in situ hybridizations were performed as previously described (Hanashima et al., 2002), using nonradioactive digoxigenin-labeled probes. The cDNA probes used included Gad67 and Lhx6.

Electrophysiology. P14-P21 mice (of various genotypes, as indicated throughout the text) were anesthetized with isoflurane and the brain dissected out in ice-cold saline solution containing the following (in mM): $80 \mathrm{NaCl}, 25 \mathrm{NaHCO}_{3}, 1.25 \mathrm{NaH}_{2} \mathrm{PO}_{4}, 3.5 \mathrm{KCl}, 4.5 \mathrm{MgSO}_{4} 0.5$ $\mathrm{CaCl}_{2}, 10$ glucose, 90 sucrose, saturated with $95 \% \mathrm{O}_{2}$ and $5 \% \mathrm{CO}_{2}, \mathrm{pH}$ 7.4. Transverse hippocampal slices $(300 \mu \mathrm{m})$ were cut using a VT-1000S vibratome (Leica) and incubated in the above solution at $35^{\circ} \mathrm{C}$ for recovery $(1 \mathrm{~h})$, after which they were kept at room temperature until use. Individual slices were transferred to an upright microscope and visualized with infrared differential interference contrast microscopy (Axioscope FS2; Zeiss). Slices were perfused $(2 \mathrm{ml} / \mathrm{min})$ with extracellular solution composed of (in mM) $130 \mathrm{NaCl}, 24 \mathrm{NaHCO}_{3}, 3.5 \mathrm{KCl}, 1.25$ $\mathrm{NaH}_{2} \mathrm{PO}_{4}, 2.5 \mathrm{CaCl}_{2}, 1.5 \mathrm{MgCl}_{2}, 5 \mathrm{Na}$-pyruvate, and 10 glucose, saturated with $95 \% \mathrm{O}_{2}$ and $5 \% \mathrm{CO}_{2}, \mathrm{pH}$ 7.4. Recordings were performed at $32-34^{\circ} \mathrm{C}$ with electrodes $(3-5 \mathrm{M} \Omega$ ) pulled from borosilicate glass (World Precision Instruments) filled with $150 \mathrm{~mm}$ K-gluconate, $4 \mathrm{~mm} \mathrm{NaCl}, 3$ $\mathrm{MgCl}_{2}, 0.5 \mathrm{EGTA}$, and $10 \mathrm{HEPES}$ plus $2 \mathrm{mg} / \mathrm{ml}$ biocytin (SigmaAldrich). The $\mathrm{pH}$ was adjusted to 7.4 with $\mathrm{KOH}$ ( $\sim 300 \mathrm{mOsm})$. Wholecell patch-clamp recordings were made using a Multiclamp 700B amplifier (Molecular Devices). Signals were filtered at $3 \mathrm{kHz}$ (Bessel filter; Frequency Devices) and digitized at $20 \mathrm{kHz}$ (Digidata $1440 \mathrm{~A}$ and pClamp 10.2 Software; Molecular Devices). Recordings were not corrected for a liquid junction potential. Resting potentials were measured immediately after breakthrough. Input resistances $\left(R_{\mathrm{m}}\right)$ was measured using a linear regression of voltage deflections $( \pm 15 \mathrm{mV}$ from resting potential, $\sim 60 \mathrm{mV}$ ) in response to $2 \mathrm{~s}$ current steps of six to 10 different amplitudes (increment, $5 \mathrm{pA}$ ). Membrane time constant $\left(\tau_{\mathrm{m}}\right)$ was calculated from the mean responses to 20 successive hyperpolarizing current pulses ( $-20 \mathrm{pA} ; 400 \mathrm{~ms})$. Time constant was determined by fitting voltage responses with a single exponential function. Membrane capacitance $\left(C_{\mathrm{m}}\right)$ was calculated according to $C_{\mathrm{m}}=\tau_{\mathrm{m}} / R_{\mathrm{m}}$. Action potential threshold was defined as the voltage at which the slope trajectory reaches 10 $\mathrm{mV} / \mathrm{ms}$ (Stuart and Häusser, 1994). Action potential amplitude was defined as the difference in membrane potential between threshold and the peak. Afterhyperpolarization (AHP) amplitude was defined as the difference between action potential threshold and the most negative membrane potential attained during the AHP. These properties were obtained from the mean value of the first two action potentials elicited by depolarizing 800-ms-long current pulse of just suprathreshold strength. The adaptation ratio was defined as the ratio of the average of the last two to three interspike intervals relative to the first interspike interval during an 800-ms-long spike train. Firing frequency was calculated as the inverse of the mean interspike interval during the same spike train. Adaptation ratio and firing frequency were calculated based on response evoked by current pulse of just above threshold strength and twice that value.

Single-cell reverse transcription-PCR. The single-cell reverse transcription-PCR (scPCR) protocol was designed to detect simultaneously the transcripts of PV, CR, calbindin, the GABA synthesizing enzymes GAD65 and 67, NPY, SOM, VIP, cholecystokinin (CCK), nNOS, and the $\mathrm{GABA}_{\mathrm{A}}$ receptor subunit $\alpha 1$ (GABAAR $\alpha 1$ ). At the end of the recording, cell cytoplasm was aspirated into the recording pipette while maintaining the tight seal. The content of the pipette was expelled into a test tube and subjected to reverse transcription (RT) and two steps of PCR as described previously (Lambolez et al., 1992; Cauli et al., 1997; Karagiannis et al., 2009). 
The cDNA present in the RT reaction were first amplified simultaneously using all primer pairs described in supplemental Table S1 (available at www.jneurosci.org as supplemental material) in a total volume of $100 \mu \mathrm{l}$ (for each primer pair, the sense and antisense primers were positioned on two different exons). A second round of PCR was then performed using $2 \mu \mathrm{l}$ of the first PCR product as a template. In the second round, each cDNA was amplified individually with a second pair of primers internal to the primer pair used in the first PCR (nested primers; see supplemental Table S1, available at www.jneurosci.org as supplemental material) and positioned on two different exons. The RT-PCR protocol was tested on 1 ng of total RNA purified from mouse whole brain. All the transcripts were detected from $1 \mathrm{ng}$ of whole-brain RNA (see Fig. $1 F$ ). The sizes of the PCR-generated fragments were as predicted by the mRNA sequences (see supplemental Table S1, available at www.jneurosci.org as supplemental material). Routinely, a control for mRNA contamination from surrounding tissue was performed by placing a patch pipette in the slice without establishing a seal. Positive pressure was then interrupted and, following the removal of the pipette, its content was processed as described. No PCR product was obtained using this protocol.

Data analysis. Immunocytochemical cell counting was performed on at least three nonconsecutive sections from at least three animals from different litters. Except for experiments with Nkx2-1 conditional mutant, two mutant animals and two control littermates were used for each time points. Values are given as mean \pm SEM.

Electrophysiological parameters were measured using procedures written in Igor 6 (Wavemetrics) and using Clampfit 10 (Molecular Devices). Differences between groups was assayed using the Kruskal-Wallis test followed by multiple-comparison post hoc tests using the software Statistica 8 (Statsoft). The level of significance (5\%) was adjusted using the Bonferroni correction.

\section{Results}

Ivy and neurogliaform cells share similar electrophysiological and molecular properties

To initially target IvCs and NGCs, we took advantage of two bacterial artificial chromosome-based transgenic lines, NPY-tauGFP (Pinto et al., 2004) and NPY-hrGFP (van den Pol et al., 2009), that express GFP under control of the NPY promoter. CA1 $\mathrm{GFP}^{+}$interneurons $(n=13 \mathrm{IvCs}$ and $35 \mathrm{NGCs})$ were visually identified and then characterized by combining patch-clamp recordings, scPCR, and biocytin labeling (Cauli et al., 1997) for physiological, molecular, and morphological identification, respectively. Their electrophysiological profile was examined using 15 features describing their intrinsic excitability and firing properties (see Materials and Methods for definitions of the parameters). The scPCR protocol was designed to detect simultaneously the transcripts of multiple interneuron markers (see Materials and Methods and supplemental Table S1, available at www. jneurosci.org as supplemental material) including nNOS and GABAAR $\alpha 1$.

Consistent with previous studies (Vida et al., 1998; Price et al., 2005), NGCs were found close to the boundaries between stratum lacunosum moleculare (s.l.m.) and stratum radiatum (s.r.), or stratum moleculare (s.m.) of the dentate gyrus, or at the border with CA3. Cells exhibited multipolar morphologies comprised of several primary dendrites emanating from the soma (Fig. 1 A). The dendritic field was typically restricted to s.l.m. with occasional dendrites penetrating s.r. or s.m. NGCs exhibited a dense axonal field with its lateral extent broader than the corresponding dendritic field. In contrast, IvCs were typically found throughout s.r., stratum pyramidale (s.p.), and stratum oriens (s.o.) with dendritic arbors that often crossed these layers without penetrating s.l.m. (Fig. $1 A$ ) as described previously (Fuentealba et al., 2008b). Similar to NGCs, the axonal plexus of IvCs comprised thin branches that formed a dense and widespread plexus covering a greater extent of the CA1 field than their dendritic tree.
scPCR analysis of morphologically identified NGCs and IvCs ( $n=35$ and 13, respectively) revealed infrequent expression of PV, CR, SOM, VIP, and CCK transcripts. Both IvCs and NGCs consistently coexpressed NPY, nNOS, and GABAAR $\alpha 1$ (Fig. $1 B, C$; supplemental Tables $\mathrm{S} 2$ and S3, available at www.jneurosci. org as supplemental material), however a subset of NGCs (10 out of 35) were nNOS-negative. Importantly, s.l.m. interneurons that lacked an NGC-like morphology $(n=15)$ were never positive for NPY or nNOS and only rarely expressed GABAAR $\alpha 1$ transcripts, confirming that this combination of markers serves as a relatively unique footprint to IvC and NGC populations.

Among the 15 electrophysiological properties measured for each IvC and NGC (IvC, $n=13$; NGC nNOS ${ }^{+}, n=25$; NGC nNOS $^{-}, n=10$; Table 1 , see Materials and Methods for definition), 13 were not significantly different between the three groups with the exception of membrane capacitance $(p=0.0026)$ and the action potential adaptation ratio (measured at twice threshold stimulation; $p=0.005$ ). Post hoc multiple-comparison tests performed within these parameters revealed a significant difference between IvCs and the two NGC groups but not between the two NGC groups. The difference in membrane capacitance likely reflects the dendritic field of IvCs that typically spreads across several layers resulting in greater total dendritic length.

NGCs are characterized by a delay to generate action potentials when challenged by just suprathreshold current injection (Fig. 1D) (Price et al., 2005; Zsiros and Maccaferri, 2005) and therefore are often named "late spiking" (LS) (Kawaguchi, 1995). All recorded NGCs, whether nNOS ${ }^{+}$or $\mathrm{nNOS}^{-}$, exhibited a LS phenotype, as did all identified IvCs (Fig. 1D). This feature, quantified as the latency to generate the first spike upon just suprathreshold stimulation, was similar for IvCs, $\mathrm{nNOS}^{+} \mathrm{NGCs}$, and $\mathrm{nNOS}^{-} \mathrm{NGCs}(511 \pm 51 \mathrm{~ms}$ vs $376 \pm 40 \mathrm{~ms}$ vs $354 \pm 66 \mathrm{~ms}$, respectively; $n=13,25,10$, respectively; $p=0.1058)$. Importantly, no significant differences were found between IvC and NGC spike thresholds, amplitudes and durations, AHP amplitudes and durations, and maximum slopes during spike repolarization (Table 1). These similarities between action potential waveforms are easily visualized in phase plots $\left(d V_{\mathrm{m}} / d t \mathrm{vs} V_{\mathrm{m}}\right)$ of firing in response to $2 \times$ threshold stimulation, which clearly indicate that IvCs and NGCs exhibit similar spike amplitude and maximum slope during the rising and repolarizing phases of action potentials (Fig. $1 E$ ). In addition, neither cell type exhibited adaptation of firing frequency at threshold stimulation and instead typically increased their firing frequency toward the end of the stimulus (adaptation ratio $\geq 1$ ) (Fig. 1D). However, upon stronger stimulation, NGCs switched to an adaptive spiking profile that was more pronounced than in IvCs (adaptation ratio at $2 \times$ threshold, $0.73 \pm 0.04$ and $0.72 \pm 0.07$ for $\mathrm{nNOS}^{+}$and $\mathrm{nNOS}^{-}$NGCs respectively vs $0.92 \pm 0.02$ for IvCs).

Taken together, our data indicate that despite residing in different hippocampal layers, IvCs and NGCs have similar dendritic and axonal features with almost identical electrophysiological properties. Moreover, IvCs and the vast majority of NGCs, the nNOS $^{+}$cohort, exhibit overlapping molecular profiles.

\section{Ivy and $\mathrm{nNOS}^{+}$neurogliaform interneurons both originate from MGE}

The common NPY expression within all NGCs and IvCs, combined with the fact that a large population of hippocampal NPY ${ }^{+}$ interneurons originate from the MGE (Fogarty et al., 2007), prompted us to consider whether IvCs and NGCs both derive from the MGE. The homeobox gene Nkx2-1 (also known as Titf1) is expressed ubiquitously throughout the MGE and is ex- 

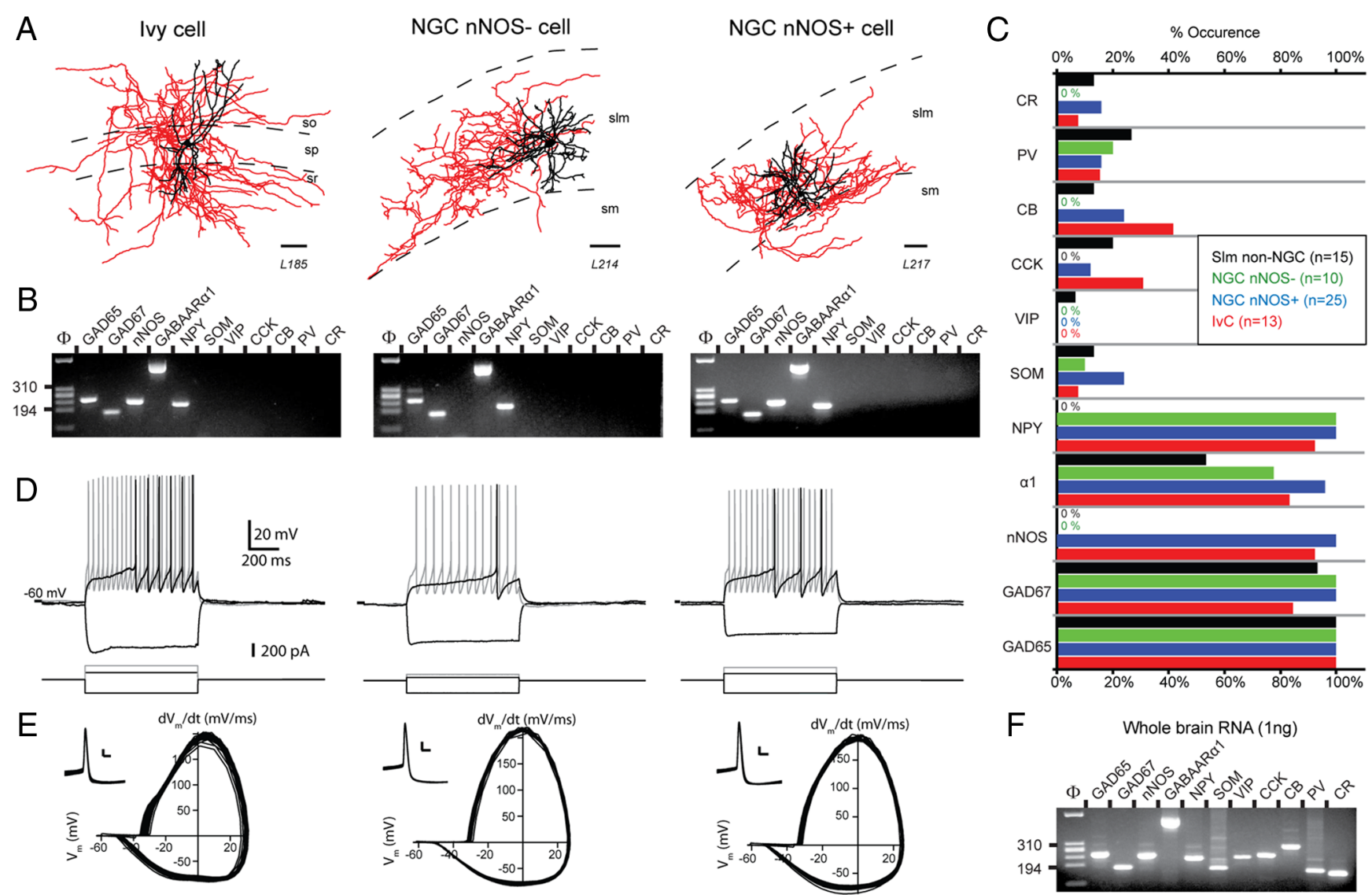

Figure 1. Anatomical, neurochemical, and electrophysiological characterization of Ivy cells and neurogliaform cells. $A$, Neurolucida reconstructions of biocytin-filled cells. Black, Dendrite; red, axon. Scale bar: $50 \mu \mathrm{m} . \boldsymbol{B}$, Neurochemical analysis of the cells shown in $A$. PCR products were resolved by agarose gel electrophoresis with $\Phi \times 174 /$ Haelll as a molecular mass marker. $C$, Summary histogram of neurochemical data obtained by single cell RT-PCR. "s.I.m. non-NGC" refers to non-NGC interneurons with cell body located in s.I.m. $\boldsymbol{D}$, Voltage responses of cells shown in $\boldsymbol{A}$ to three current step injections ( $-200 \mathrm{pA}$, just suprathreshold, and twice the current for just suprathreshold). $\boldsymbol{E}$, Phase plots of the voltage responses shown in $\boldsymbol{D}$ to twice threshold stimulation. Inset illustrates overlaid action potentials; scale bar: $10 \mathrm{mV}, 2 \mathrm{~ms}$. F, Positive control of the single-cell RT-PCR procedure performed using $1 \mathrm{ng}$ of whole brain RNA.

Table 1. Electrophysiological properties of identified IvC and NGC

\begin{tabular}{lccc}
\hline & $\begin{array}{l}\text { IVC } \\
(n=13)\end{array}$ & $\begin{array}{c}\text { NGF nNOS } \\
(n=25)\end{array}$ & $\begin{array}{c}\text { NGF nNOS }^{-} \\
(n=10)\end{array}$ \\
\hline Resting potential (mV) & $-63 \pm 1$ & $-60 \pm 2$ & $-67 \pm 2$ \\
Input resistance $(\mathrm{M} \Omega)$ & $185 \pm 14$ & $251 \pm 19$ & $228 \pm 22$ \\
Membrane capacitance (pF) & $107 \pm 11^{*}$ & $64 \pm 7$ & $62 \pm 8$ \\
Time constant (ms) & $19 \pm 1$ & $17 \pm 3$ & $13 \pm 1$ \\
Spike threshold (mV) & $-33 \pm 1$ & $-30 \pm 1$ & $-31 \pm 1$ \\
Spike amplitude $(\mathrm{mV})$ & $56 \pm 2$ & $58 \pm 1$ & $57 \pm 3$ \\
Spike half-width (ms) & $0.80 \pm 0.04$ & $0.92 \pm 0.06$ & $0.75 \pm 0.03$ \\
Maximal decay slope (mV/ms) & $-71 \pm 4$ & $-72 \pm 4$ & $-80 \pm 7$ \\
AHP amplitude (mV) & $21.4 \pm 0.6$ & $21.8 \pm 0.4$ & $21.9 \pm 1.4$ \\
AHP half-width (ms) & $73 \pm 6$ & $63 \pm 6$ & $81 \pm 15$ \\
Minimal frequency (Hz) & $7.9 \pm 0.7$ & $7.8 \pm 0.5$ & $8.2 \pm 1.4$ \\
Adaptation ratio at threshold & $1.22 \pm 0.05$ & $1.14 \pm 0.10$ & $1.01 \pm 0.06$ \\
Frequency at $2 \times$ threshold $(\mathrm{Hz})$ & $32 \pm 2$ & $38 \pm 3$ & $40 \pm 7$ \\
Adaptation ratio at $2 \times$ threshold & $0.92 \pm 0.02^{*}$ & $0.73 \pm 0.04$ & $0.72 \pm 0.07$ \\
First spike latency $(\mathrm{ms})$ & $511 \pm 51$ & $376 \pm 40$ & $354 \pm 66$ \\
\hline
\end{tabular}

*IVC significantly different from NGF nNOS ${ }^{+}$and nNOS ${ }^{-}$

cluded from the lateral ganglionic eminence (LGE) and CGE. It has been proposed that $N k \times 2-1$ acts as a molecular switch that favors MGE fate over CGE fate (Butt et al., 2008). To investigate the developmental origins of IvCs and NGCs, we used a combined genetic fate-mapping and immunocytochemical approach. We crossed an Nkx2-1BAC-Cre driver line (Xu et al., 2008) with the newly developed Cre-dependent GFP reporter line RCE:LoxP (Sousa et al., 2009) to confer permanent labeling of Nkx2-1expressing precursors with GFP to examine the fate of MGEderived interneurons in the mature hippocampus. We then stained hippocampal sections for a variety of classic interneuron markers. In CA1 of adult hippocampus, the majority $(73 \%)$ of $\mathrm{GFP}^{+}$cells were located in s.o. and s.p. $(35 \pm 3 \%$ and $38 \pm 1 \%$, respectively, of the total number of CA1 $\mathrm{GFP}^{+}$interneurons vs $16 \pm 1$ and $11 \pm 1 \%$ in s.r. and s.l.m.; $n=1992$ ) (Fig. $2 A)$. As observed in other studies using a different MGE driver line (Fogarty et al., 2007) or a different reporter line (Xu et al., 2008), all PV ${ }^{+}$ interneurons were also $\mathrm{GFP}^{+}$(Fig. $2 \mathrm{~B}$ ), and a similar coexpression pattern was observed for $\mathrm{SOM}^{+}$interneurons (data not shown), confirming the reliability of the Nkx2-1BAC-Cre/RCE:LoxP construct for labeling MGE-derived interneuron precursors.

Next, because IvCs and NGCs combined represent the majority of $\mathrm{nNOS}^{+}$hippocampal interneurons, we compared the expression pattern of nNOS and GFP in our Nkx2-1BAC-Cre/RCE: LoxP cross. In contrast to $\mathrm{PV}^{+}$and $\mathrm{SOM}^{+}$interneurons, nNOS ${ }^{+}$ interneurons were found throughout all the layers of CA1 (Fig. $2 C)$. On average, nNOS $^{+}$interneurons comprised $37 \pm 2 \%$ of $\mathrm{GFP}^{+}$interneurons $(n=1992)$ (Fig. $\left.2 D\right)$. Within the s.l.m., this percentage rose to $94 \pm 2 \%$ but dropped to $23 \pm 2 \%$ and $25 \pm 3 \%$ in s.o. and s.p., respectively. Conversely, $75 \pm 1 \%$ of CA1 nNOS ${ }^{+}$ interneurons were also $\mathrm{GFP}^{+}(n=990)$ (Fig. $\left.2 C, D\right)$. The vast majority of $\mathrm{nNOS}^{+}$interneurons derived from $N k \times 2-1$ progenitors were found in the s.o., s.r., and s.l.m., with a smaller percentage 
Nkx2-1BAC-Cre/RCE:LoxP
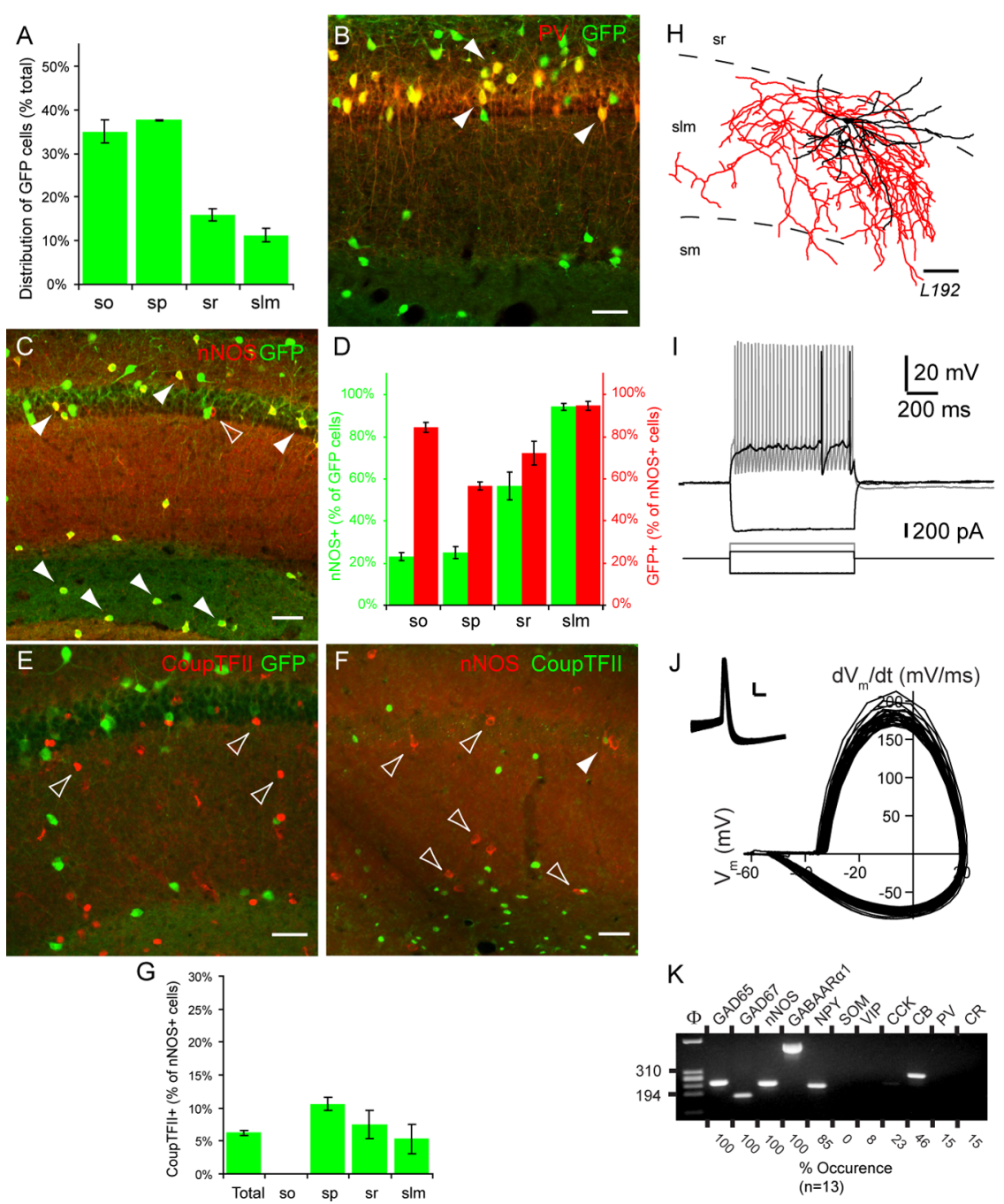

Figure 2. Interneurons expressing nNOS belong to an MGE lineage. $\boldsymbol{A}$, Histogram showing the distribution of GFP-positive cells in CA1 of NkX2-1BAC-Cre/RCE:LoxP mice ( $n=1992)$. $B$, C, Images illustrating the coexpression between GFP, PV, and nNOS. Filled arrowheads indicate interneurons expressing PV $(\boldsymbol{B})$ or nNOS (C) and GFP. Transparent arrowheads point to PV (or nNOS)-positive interneurons that are negative for GFP. $\boldsymbol{D}$, In green, the number of Nkx2-1-derived cells coexpressing GFP and nNOS presented as a percentage of the total number of GFP ${ }^{+}$cells. In red, the contribution of Nkx2-1-expressing precursors to the population of $\mathrm{nNOS}^{+}$interneurons in CA1 $(n=990)$. $\boldsymbol{E}, \boldsymbol{F}$, Images illustrating the low coexpression between CoupTFIl with GFP and nNOS. $\boldsymbol{G}$, Fraction of interneurons coexpressing CoupTFIl and nNOS presented as a percentage of the total number of nNOS ${ }^{+}$cells $(n=$ 695). $\boldsymbol{H}$, Neurolucida reconstruction of a NGC GFP ${ }^{+}$interneuron. Scale bar: $50 \mu \mathrm{m}$. $\boldsymbol{I}$, Voltage responses of cell shown in $\boldsymbol{H}$ to three current step injections ( $-200 \mathrm{pA}$, just suprathreshold, and twice the suprathreshold current). J, Phase plot of the voltage response shown in $\boldsymbol{H}$ to the $2 \times$ suprathreshold current. Inset illustrates overlaid action potentials; scale bar: $10 \mathrm{mV}, 2 \mathrm{~ms}$. $\boldsymbol{K}$, Single-cell RT-PCR analysis of the cell shown in $\boldsymbol{H}$. The numbers under the gel represent the summary data for all tested GFP ${ }^{+}$interneurons recorded in s.l.m. Scale bars: $50 \mu \mathrm{m}$.

of $\mathrm{nNOS}^{+}$interneurons within s.p. being $\mathrm{GFP}^{+}$(e.g., $57 \pm 2 \%$ and $95 \pm 2 \%$ of $\mathrm{nNOS}^{+}$cells colocalized GFP in s.p. and s.l.m., respectively) (Fig. 2D).

To investigate a potential CGE origin of $\mathrm{nNOS}^{+}$interneurons, we additionally compared nNOS and the chicken ovalbumin upstream-transcriptional factor II (CoupTFII, also known as Nr2f2 or Arp-1) expression patterns. CoupTFII is expressed in the CGE and remains detectable during interneuron migration (Kanatani et al., 2008; Willi-Monnerat et al., 2008) as well as in a subset of mature hippocampal interneurons (Fuentealba et al., 2008a; Kanatani et al., 2008). In contrast to nNOS, the expression pattern of CoupTFII was complementary to that of GFP in $N k \times 2-1 / R C E-l o x-P$ offspring with very few CoupTFII ${ }^{+}$interneu- rons being $\mathrm{GFP}^{+}$(Fig. 2E). Thus, CoupT$\mathrm{FII}^{+}$interneurons are not MGE-derived, confirming CoupTFII as a useful marker of CGE lineage. Consistent with the low colocalization between CoupTFII and GFP, we found that only $6 \pm 1 \%$ of $\mathrm{nNOS}^{+}$interneurons coexpressed CoupTFII $(n=695)$ (Fig. $2 F, G)$. The highest percentage of CoupTFII/nNOS ${ }^{+}$colocalization was found in s.p., where GFP/nNOS coexpression was lowest. These data further indicate that most $\mathrm{nNOS}^{+}$interneurons originate from the MGE with only a small fraction deriving from CGE progenitors.

To confirm whether $\mathrm{GFP}^{+}$s.l.m. interneurons in the Nkx2-1BAC-Cre/RCE: LoxP mouse are indeed NGCs, we targeted $\mathrm{GFP}^{+}$cells in acute brain slices from these mice for whole-cell patch-clamp recordings to perform electrophysiological scPCR and post hoc morphological characterization $(n=13)$. All tested $\mathrm{GFP}^{+}$ cells exhibited NGC morphologies (Fig. $2 \mathrm{H}$ ) and LS profiles (Fig. $2 \mathrm{I}$ ) that yielded phase plots (Fig. $2 J$ ) similar to IvCs and NGCs recorded in NPY-GFP mice (compare Fig. $1 D$ ). Moreover, the molecular profile of s.l.m. GFP ${ }^{+}$cells was typified by a high occurrence of NPY, nNOS, and GABAAR $\alpha 1$ (Fig. $2 K$; supplemental Table S4, available at www.jneurosci.org as supplemental material). These properties are all consistent with NGCs and combined with our immunocytochemical

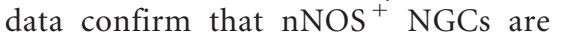
MGE-derived.

\section{Spatial and temporal origins of nNOS ${ }^{+}$interneurons}

In addition to the place of birth, a growing body of evidence suggests that interneuron identity is specified in the embryonic brain in a temporally dependent manner (Butt et al., 2005; Miyoshi et al., 2007). Olig2 is a basic helix-loop-helix transcription factor ( $\mathrm{Lu}$ et al., 2002) expressed in progenitors of the ventral embryonic eminences, with the highest levels of expression occurring in the MGE. Using a driver allele expressing a tamoxifen-inducible form of Cre recombinase (CreER) under control of the endogenous Olig2 locus (Olig2CreER) (Takebayashi et al., 2002), crossed with the Cre-dependent GFP reporter allele Z/EG (Novak et al., 2000), we next performed inducible genetic fate mapping (Joyner and Zervas, 2006) of the temporally distinct cohorts of MGE-derived precursors (Miyoshi et al., 2007) to further verify the MGE origin of nNOS ${ }^{+}$interneurons and probe for any temporal order to the birth of these cells. Pregnant females received a single dose of tamoxifen by gavaging at different time points between E9.5 and E13.5, and then $\mathrm{GFP}^{+}$cells were characterized in 3-4-week-old animals. For all tested time points, this fatemapping strategy resulted in GFP labeling of just a few interneurons throughout the hippocampus. In the dentate gyrus and CA3, 
Olig2 ${ }^{\text {CreER/ZEG }}$

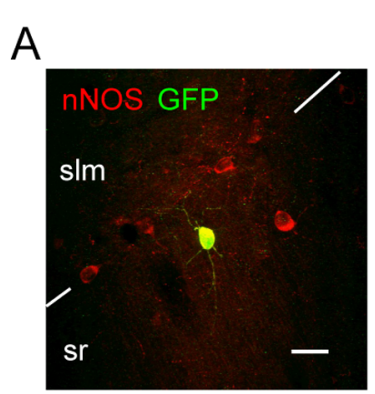

B

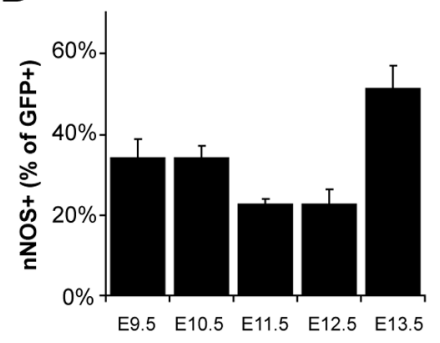

C
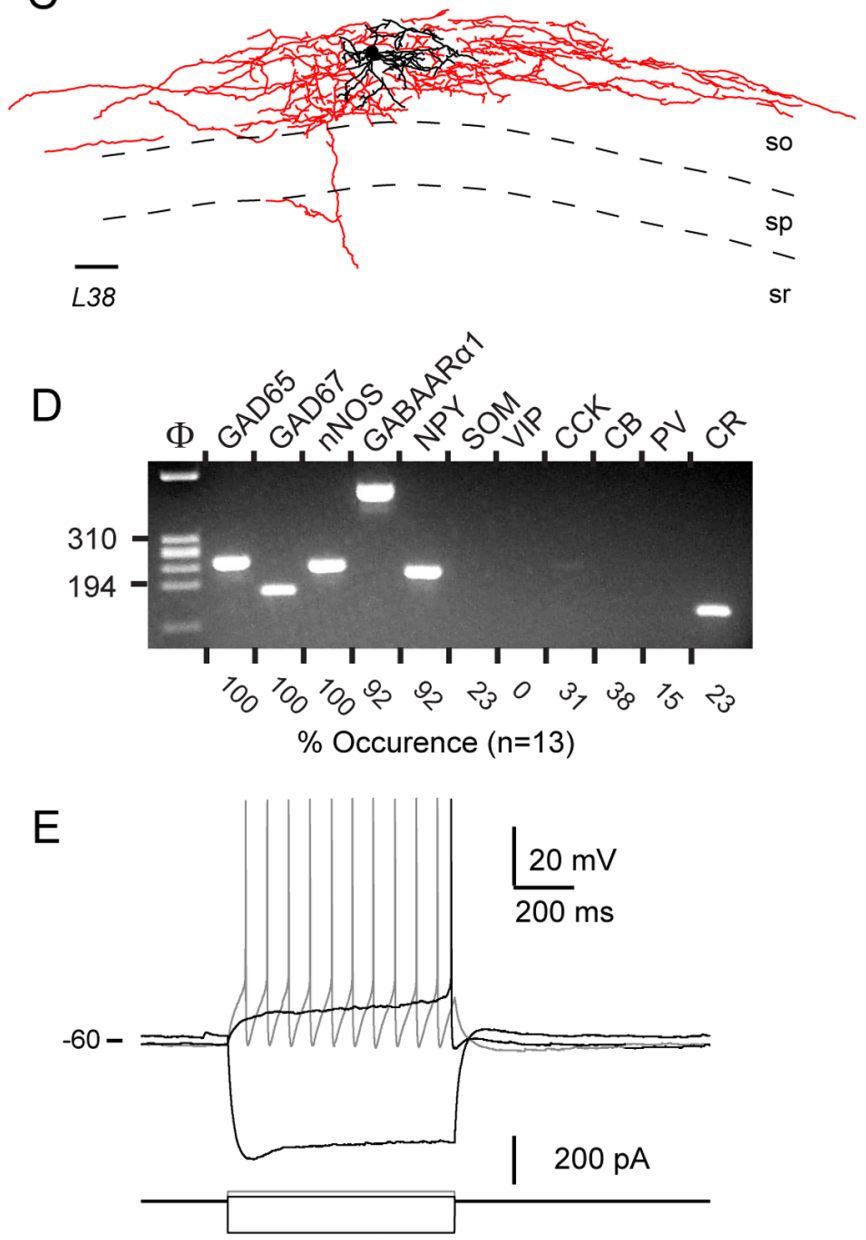

$\mathrm{F}$

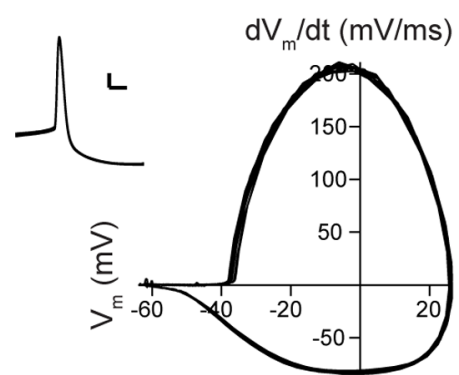

Figure 3. Inducible genetic fate mapping of MGE-derived $\mathrm{nNOS}^{+}$interneurons. $A$, Example of nNOS expression in fate-mapped interneurons in mature hippocampus of Olig2 ${ }^{\text {CreER/ZZG }}$ mouse after tamoxifen administration at E10.5. Scale bar: $25 \mu \mathrm{m} . \boldsymbol{B}$, Contribution of nNOS ${ }^{+}$interneurons to the cohort arising from MGE between E9.5 and E13.5. C, Neurolucida reconstruction of a fate mapped Ivy cell in Olig2 ${ }^{\text {reER } / Z E G ~ m o u s e ~ a f t e r ~ i n d u c t i o n ~ a t ~ E 11.5 . ~ S c a l e ~ b a r: ~} 50 \mu \mathrm{m}$. D, Single-cell RT-PCR analysis of the cell shown in $C$. Numbers under the gel represent the summary data for all fate-mapped lvy cells. we found fate-mapped cells in all the layers. In CA1, GFP ${ }^{+}$cells preferentially localized in s.o. and s.p.

A significant fraction of fate-mapped interneurons at each time point was $\mathrm{nNOS}^{+}$(Fig. $3 A, B$ ). Indeed, $\mathrm{nNOS}^{+}$cells represented $\sim 34 \%$ of the populations fate mapped at early time points (E9.5 and E10.5; $n=79$ each) but decreased in number to $\sim 20 \%$ at intermediate time points (E11.5 and E12.5; $n=124$ and 79, respectively) and then finally peaked at $51 \%$ after tamoxifen induction at the latest time point examined (E13.5; $n=39$ ). In agreement with lineage analysis of Nkx2-1-expressing interneuron precursors, we found $\mathrm{nNOS}^{+}$fate-mapped interneurons in all layers of CA1. To confirm the identity of these spatially and temporally fate-mapped interneurons, we recorded and analyzed $46 \mathrm{GFP}^{+}$interneurons from 2-3-week-old animals that had undergone tamoxifen administration between E9.5 and E13.5. Thirteen of $46 \mathrm{GFP}^{+}$cells were positive for nNOS (supplemental Table S4, available at www.jneurosci.org as supplemental material), and most of these cells were also positive for NPY and the GABAAR $\alpha 1$ transcripts ( 12 out of 13 for each marker). Importantly, virtually all cells displayed a LS phenotype, characteristic of $\mathrm{nNOS}^{+}$cells recorded in NPY-GFP mice. The morphology of six out of seven interneurons, located in s.r. and s.o., was successfully recovered, allowing their classification as IvCs (Fig. $3 C-F$ ). Cells located in the s.l.m. all exhibited firing and molecular profiles consistent with NGCs and, in three out of six cells, their NGC morphology was confirmed (supplemental Fig. S1 and Table S4, available at www.jneurosci.org as supplemental material). Taken together, these data again point to a common MGE origin of IvCs and $\mathrm{nNOS}^{+} \mathrm{NGCs}$ and further indicate that the temporal origins of these cells exhibit a biphasic pattern.

\section{Nkx2-1 requirement for the generation of IvCs and NGCs}

The transcription factor Nkx2-1 and its downstream effector, the Lim homeodomain protein Lhx6, are required for the proper specification and migration of MGE-derived interneurons (Pleasure et al., 2000; Liodis et al., 2007; Butt et al., 2008). Previous studies on embryonic neocortex and hippocampus have found that loss of Nkx2-1 function results in loss of $\mathrm{NPY}^{+}$and $\mathrm{nNOS}^{+}$cortical interneurons (Pleasure et al., 2000; Anderson et al., 2001). However, lineage analysis showed that NPY ${ }^{+}$interneurons exhibit dual MGE/CGE origin (Butt et al., 2005; Fogarty et al., 2007). Given the molecular diversity of neocortical nNOS and NPY interneurons (Lee and Jeon, 2005; Karagiannis et al., 2009) and the essentially postnatal development of hippocampal NPY and nNOS expression patterns (Soriano et al., 1994; Moryś et al., 2002), we investigated further the role of Nkx2-1 on specification of IvCs and NGCs in mature hippocampus when NPY and nNOS phenotypes are fully established. Because Nkx2-1 knock-out mice die at birth, we used an Nkx2-1 loxP-flanked conditional loss-of-function allele (Kusakabe et al., 2006) together with a genetic fate-mapping strategy to examine the role of Nkx2-1 in specifying the fate of $\mathrm{nNOS}^{+}$precursors. By crossing the Olig2CreER driver line onto an Nkx2-1 conditionally null background, we were able to genetically remove Nkx2-1 gene function from the MGE progenitor population during the period of cortical interneuron genesis (Butt et al., 2008). Although the use of this strategy overcomes the issue of perinatal lethality, mutant pups exhibit a large decrease in the number of GABAergic

$\leftarrow$

$\boldsymbol{E}$, Voltage responses of cell shown in C to three current step injections ( $-150 \mathrm{pA}$, just suprathreshold, and twice threshold stimulation). $\boldsymbol{F}$, Phase plot of the voltage response shown in $\boldsymbol{E}$ to $2 \times$ suprathreshold current injection. Inset illustrates overlaid action potentials; scale bar: $10 \mathrm{mV}, 2 \mathrm{~ms}$. 
A
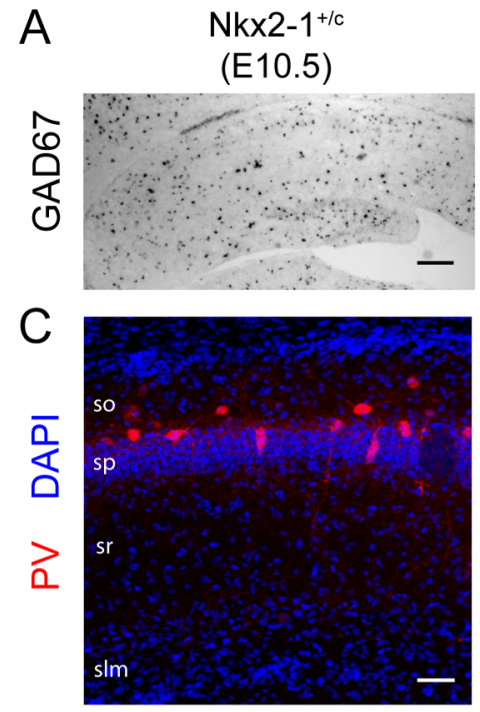

$\mathrm{E}$

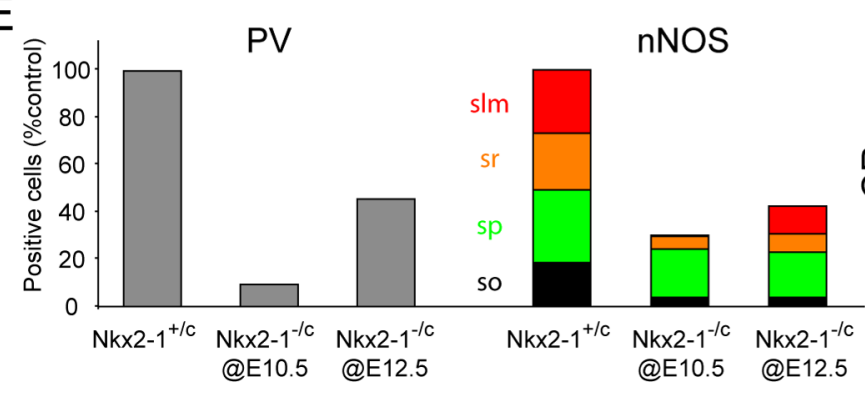

$\mathrm{Nkx2-1/c \textrm {c }}$

(E10.5)
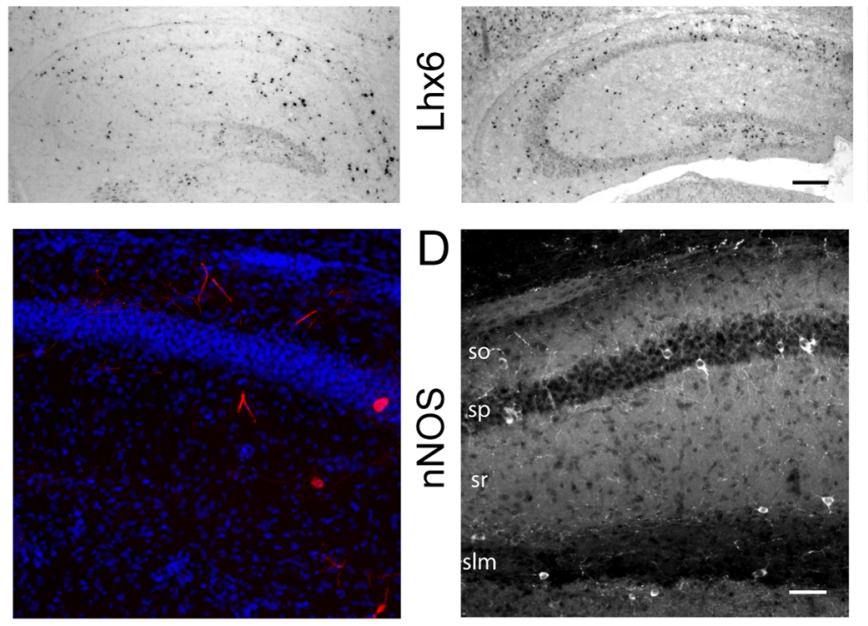

$\mathrm{F}$

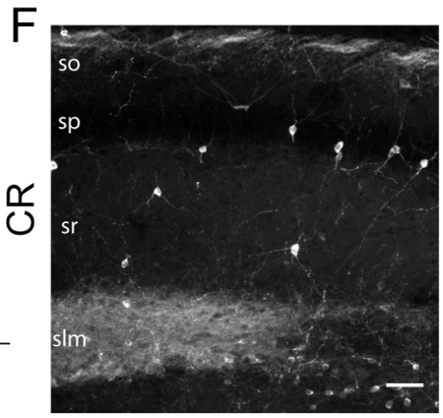

Nkx2-1/c

(E10.5)
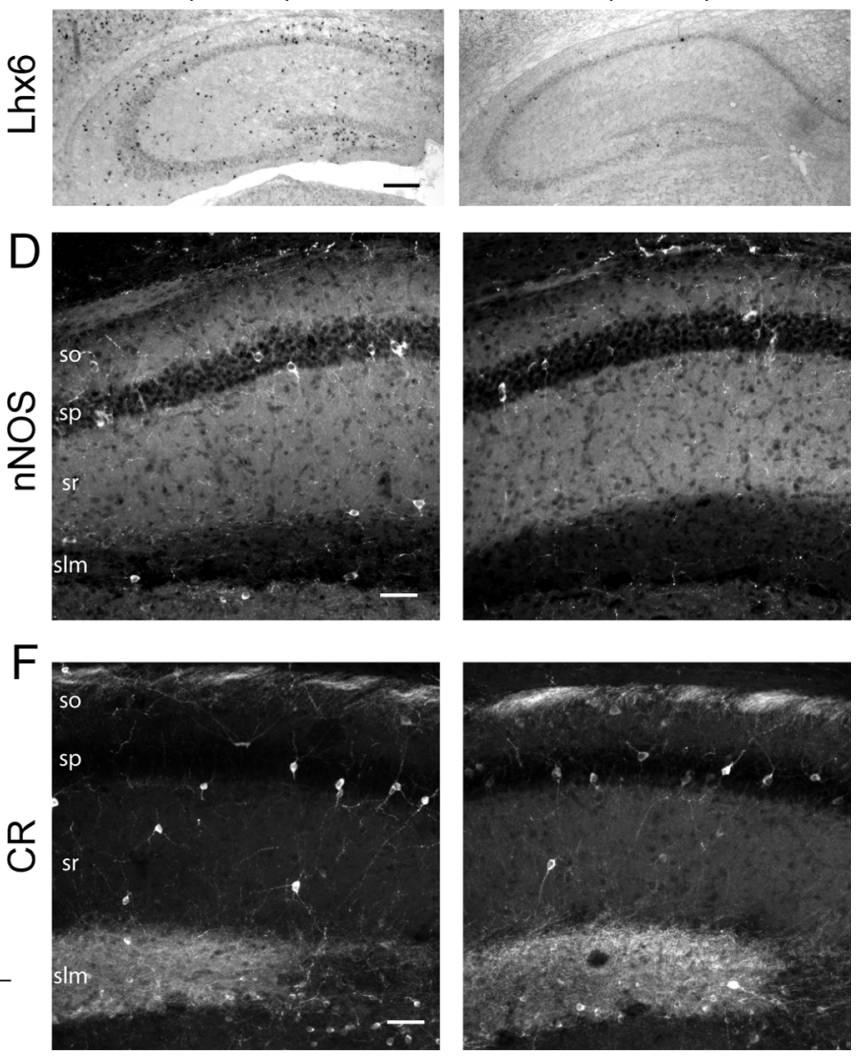

Figure 4. Nkx2-1 is necessary for the specification of nNOS ${ }^{+}$interneurons. $\boldsymbol{A}, \boldsymbol{B}$, In situ hybridization against GAD67 and Lhx6 transcripts on hippocampus of Nkx2-1 $+/ c$ control (left) and Nkx2-1 ${ }^{-/ c}$ mutant (right) P15 mice after loss of Nkx2-1 function at E10.5. C, D, Immunohistochemical expression patterns of PV and nN0S in CA1 of control and mutant mice after tamoxifen induction at E10.5. $\boldsymbol{E}$, Summary histogram of relative abundance of PV ${ }^{+}$and nNOS ${ }^{+}$interneurons in CA1 of control and mutant littermates after loss of Nkx2-1 function at E10.5 and E12.5. $\boldsymbol{F}$, Expression pattern of CR in CA1 of control and mutant mice after tamoxifen induction at E10.5. Scale bars: $\boldsymbol{A}, \boldsymbol{B}, 200 \mu \mathrm{m} ; \boldsymbol{C}, \boldsymbol{D}$, and $\boldsymbol{F}, 50 \mu \mathrm{m}$.

interneurons in the cortex and hippocampus (Fig. 4A) precipitating seizures and poor survival after 2 weeks of age after tamoxifen-mediated Cre activation at E9.5 or E10.5 (Butt et al., 2008). Therefore, we compared the abundance of different hippocampal PV, CR, and nNOS interneuron subpopulations in P13P15 mutant animals (genotype: Olig2CreER ${ }^{+/-}: \mathrm{Nkx} 2-1^{\mathrm{flx} /-}$ ) induced at E10.5, with control littermates (genotype: Olig2CreER ${ }^{+1}$ $-: \mathrm{Nkx} 2-1^{\mathrm{flx} /+}$ ). We also compared the effects of Nkx2-1 deletion at E10.5 with the results of the deletion at E12.5 in P21 animals.

Although the loss of Nkx2-1 function does not decrease the total number of GABAergic neurons generated during embryogenesis (Butt et al., 2008), it significantly reduces the number of MGE-derived cortical interneurons in the hippocampus at postnatal stages, as indicated by a large reduction in the number of Lhx $6^{+}$interneurons (Fig. 4B). As expected, we observed a massive reduction in the number of $\mathrm{PV}^{+}$interneurons in the whole hippocampus after removal of Nkx2-1 at E10.5 (10\% of control) (Fig. $4 C, E$ ). The loss of $\mathrm{PV}^{+}$interneurons was still evident but considerably more moderate in mutant mice induced at E12.5 ( $46 \%$ of control). We also found a large decrease in the number of $\mathrm{nNOS}^{+}$cells in mutants induced at E10.5 (30\% of control) (Fig. $4 D, E)$, consistent with an MGE-dominant origin of $\mathrm{nNOS}^{+}$interneurons. This loss of $\mathrm{nNOS}^{+}$interneurons was most prominent in s.o., s.r., and s.l.m. (Fig. $4 D, E$ ). Interestingly, the vast majority of $\mathrm{nNOS}^{+}$cells remaining in the mutant mice were located in s.p., the layer where most $\mathrm{nNOS}^{+} \mathrm{GFP}^{-}$cells were observed in the Nkx2-1BAC-Cre/RCE:LoxP mouse (compare Fig.
$3 B)$. Indeed, quantification confirmed that the reduction of $\mathrm{nNOS}^{+}$interneurons in s.p. was the smallest $(-46 \%$ vs -67 , -79 , and $-97 \%$ of control after induction at E10.5 in s.p., s.o., s.r., and s.l.m., respectively) (Fig. 4E), suggesting that s.p. $\mathrm{nNOS}^{+}$interneurons were preferentially spared by the deletion of Nkx2-1. As with $\mathrm{PV}^{+}$interneurons, the loss of $\mathrm{nNOS}^{+}$interneurons in mutant mice induced at E12.5 was less pronounced but still evident ( $42 \%$ of control) (Fig. $4 E$ ). As a control, we examined the effect of Nkx2-1 loss of function on the distribution of $\mathrm{CR}^{+}$interneurons that originate from the CGE. In contrast with $\mathrm{PV}^{+}$cells, no significant decrease in the distribution of $\mathrm{CR}^{+}$interneurons was observed in mutants induced at E10.5 (Fig. $4 F$ ) and E12.5, confirming that the loss of Nkx2-1 affects primarily MGE-derived interneurons. Altogether, our loss of function results demonstrate that $\mathrm{Nkx} 2-1$ is crucial to the specification of $\mathrm{nNOS}^{+}$interneurons and in particular IvCs and $\mathrm{nNOS}^{+} \mathrm{NGCs}$, further confirming the MGE origin of these two cell populations.

\section{nNOS is expressed in a subset of VIP-expressing bipolar interneurons}

The colocalization of CoupTFII/nNOS and the presence of $\mathrm{nNOS}^{+} / \mathrm{GFP}^{-}$cells in the Nkx2-1BAC-Cre/RCE:LoxP mouse indicate that an additional subset of $\mathrm{nNOS}^{+}$interneurons originate from the CGE. Thus, we examined the overlap of nNOS expression with VIP, a marker encountered in CGE-derived interneurons (Xu et al., 2004; Butt et al., 2005). We found that a small 

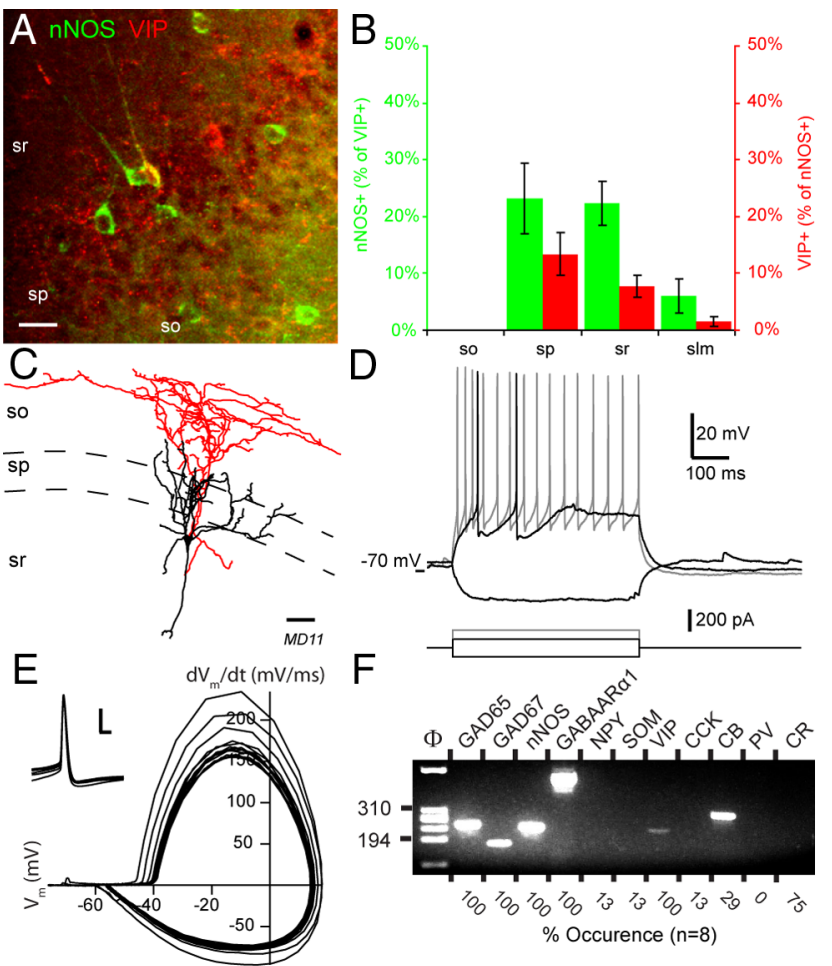

Mash1BAC-CreER/RCE:LoxP
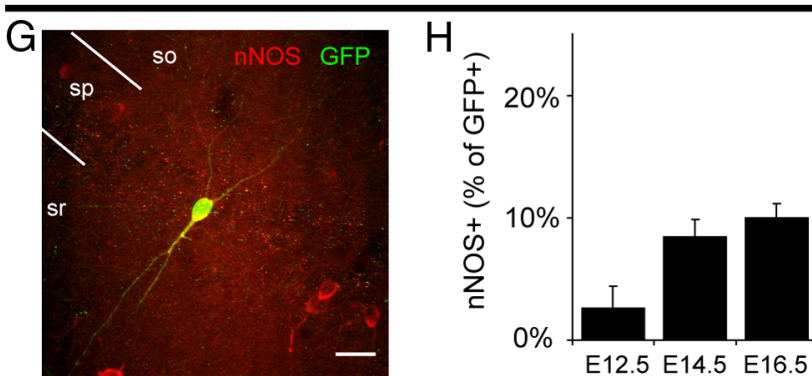

Figure 5. A subset of nNOS ${ }^{+}$interneurons derive from the CGE and coexpresses VIP. $\boldsymbol{A}$, Image illustrating the coexpression of VIP and nNOS in wild-type mouse. Scale bar: $25 \mu \mathrm{m} . \boldsymbol{B}$, In green, the number of cells coexpressing nNOS and VIP presented as a percentage of the total number ofVIP ${ }^{+}$cells $(n=240)$.In red, contribution ofVIP-expressing interneurons to the population of nNOS ${ }^{+}$cells in CA1 $(n=631)$ C, Neurolucida reconstruction of a $\mathrm{VIP}^{+} / \mathrm{nNOS}^{+}$interneuron following electrophysiological recording. $\boldsymbol{D}$, Voltage responses of cell shown in $\mathbf{C}$ to three current step injections ( $-80 \mathrm{pA}$, just suprathreshold, and twice suprathreshold stimulation). $\boldsymbol{E}$, Phase plot of the voltage response shown in $\boldsymbol{D}$ to $2 \times$ suprathreshold current injection. Inset illustrates overlaid action potentials; scale bar: $10 \mathrm{mV}, 2 \mathrm{~ms}$. $\boldsymbol{F}$, Single-cell RT-PCRanalysis of the cell shown in C. Numbers under the gel give the RT-PCR summary data for all $\mathrm{VIP}^{+} / \mathrm{nNOS}^{+}$interneurons recorded. G, Example of nNOS expression in fate-mapped interneurons in mature hippocampus of Mash1BAC-CreER/RCE:LoxP mouse after tamoxifen administration at E16.5. Scale bar: $25 \mu \mathrm{m}$. $\boldsymbol{H}$, Contribution of nNOS ${ }^{+}$interneurons to the cohort arising from CGE between E12.5 and E16.5.

fraction of CA1 $\mathrm{nNOS}^{+}$cells also express VIP $(7 \pm 1 \% ; n=631)$ (Fig. 5A,B). Conversely, interneurons coexpressing the two markers represented $17 \pm 2 \%$ of all VIP ${ }^{+}$cells $(n=240)$. This percentage rose to $23 \pm 6 \%$ when considering cells in s.p. alone, indicating that $\mathrm{nNOS}^{+} / \mathrm{VIP}^{+}$cells represent a significant portion of the $\mathrm{VIP}^{+}$interneuron population. This distribution of $\mathrm{nNOS}^{+} / \mathrm{VIP}^{+}$interneurons between CA1 layers is similar to the distribution of $\mathrm{nNOS}^{+} \mathrm{CGE}$-derived interneurons observed with CoupTFII staining (Fig. 5B; compare Fig. 2 F).

To further characterize this cell population, we took advantage of a GAD65-GFP transgenic line in which GFP is expressed in a subset of CGE-derived interneurons to target CGE-derived
$\mathrm{VIP}^{+}$interneurons (López-Bendito et al., 2004; Xu and Callaway, 2009). Of $38 \mathrm{GFP}^{+}$recorded cells analyzed by scPCR, we found both nNOS and VIP mRNAs in eight cells. PV, SOM, and NPY were rarely detected, whereas CR was found in $75 \%$ of the cells ( $n=6$ out of 8 ) (Fig. 5; supplemental Fig S2, available at www. jneurosci.org as supplemental material). The morphology of four cells was recovered and none showed morphology consistent with IvCs or NGCs (Fig. 5C). Typically, somas were located in s.p. or in s.r. close to the pyramidal layer and the dendritic fields were vertically oriented with primary axon descending to emit several horizontally oriented branches at the s.o.-alveus border. These morphological features, combined with VIP expression, are reminiscent of the interneuron population that has been reported to synaptically target other interneurons (Freund and Buzsáki, 1996). Moreover, $\mathrm{VIP}^{+} / \mathrm{nNOS}^{+}$cells exhibited diverse firing properties but importantly none had a LS phenotype (Fig. 5D, E; supplemental Fig. S2, available at www.jneurosci.org as supplemental material). Thus, the small subset of CGE-derived $\mathrm{nNOS}^{+}$interneurons is unlikely to contribute to the IvC and NGC populations.

To examine the temporal origin of CGE-derived $\mathrm{nNOS}^{+}$interneurons, we used a driver line in which CreER is under transcriptional control of a $300-\mathrm{kb}$-long promoter fragment of the basic helix-loop-helix transcription factor Mash1 (Ascl1) (Battiste et al., 2007). Although Mash1 is expressed throughout the subventricular area of the ventral telencephalon (Guillemot et al., 1993), this driver allele, crossed with the RCE:LoxP reporter allele, labels only Mash1-expressing cells in the CGE and LGE but not in the MGE (Miyoshi et al., 2010). Given that the LGE does not generate appreciable numbers of cortical interneurons, we used this driver allele in combination with the RCE:LoxP reporter to study expression of the temporally distinct cohort of CGEderived interneurons in 4-6-week-old animals after tamoxifen administration at E12.5, E14.5, and E16.5 $(n=326,690$, and 726, respectively). In contrast with the localization of $\mathrm{Nkx} 2-1$ expressing interneurons and in agreement with our CoupTFII expression pattern, CA1 fate-mapped cells were mainly found in s.r. and s.l.m. $(29 \pm 1 \%$ and $49 \pm 3 \%$ of total GFP cells after induction at E14.5; $n=357)$. We found that $\mathrm{nNOS}^{+} / \mathrm{GFP}^{+}$ interneurons typically exhibited a bipolar or vertically oriented morphology (Fig. 5G) and constituted only a small fraction of the CGE-derived interneuron population (E12.5: $3 \pm 2 \%$, E14.5 = $8 \pm 1 \%$, E16.5 $=10 \pm 1 \%$ ) (Fig. $5 H)$. Interestingly, the distribution of fate-mapped cells that expressed nNOS $^{+}$differed from the general localization of $\mathrm{GFP}^{+}$CGE-derived interneurons, being mainly found in s.p. and s.r. $(41 \pm 10 \%$ and $28 \pm 7 \%$ of total nNOS $^{+}$cells after induction at E14.5; $n=56$ ). However, this distribution of $\mathrm{nNOS}^{+} \mathrm{CGE}^{-}$derived interneurons overlaps with the distribution of $\mathrm{nNOS}^{+} / \mathrm{CoupTFII}^{+}$interneurons, indicating that a small subset of nNOS ${ }^{+}$interneurons are generated in the CGE.

Our data show that a small fraction of $\mathrm{nNOS}^{+}$interneurons arises from the CGE at later embryonic stages than the nNOS ${ }^{+}$ NGC and IvC populations. In addition, the anatomy, laminar organization, and molecular and electrophysiological properties of these CGE-derived nNOS ${ }^{+}$cells are inconsistent with those of IvC and NGC populations. Taken together, these findings indicate that $\mathrm{VIP}^{+} / \mathrm{nNOS}^{+}$cells constitute an interneuron subpopulation distinct from IvCs and NGCs.

A subset of $\mathrm{nNOS}^{-}$neurogliaform cells arises from the CGE Lineage analyses using genetic (Fogarty et al., 2007) and transplant (Butt et al., 2005) approaches have shown that a large number of $\mathrm{NPY}^{+}$interneurons derive from the MGE. However, removal of Lhx6 only mildly affects the NPY ${ }^{+}$interneuron pop- 


\section{Mash1BAC-CreER/RCE:LoxP}

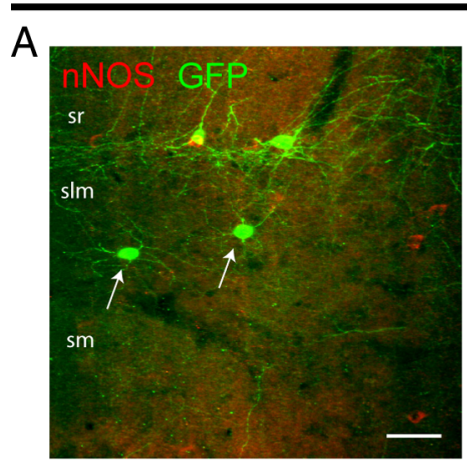

\section{$\mathrm{B}$}

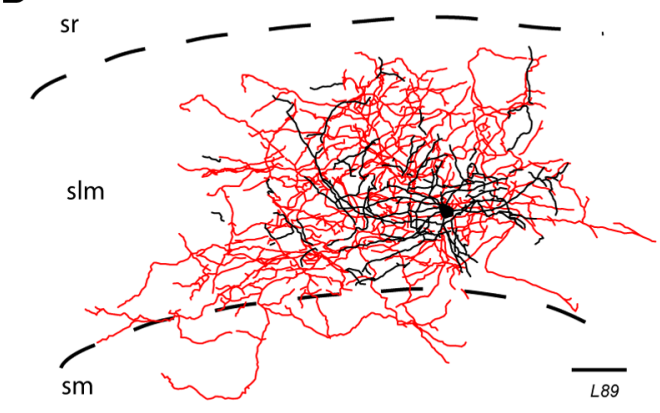

C

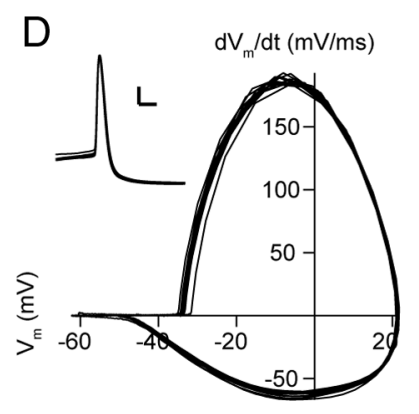

Figure 6. A subset of NGC derives from the CGE. A, Fluorescence image of two fate-mapped cells derived from Mash1 fate mapping (tamoxifen induction at E14.5) that exhibit neurogliaform morphology and that are nNOS-negative. $\boldsymbol{B}$, Neurolucida reconstruction of a fate-mapped NGC in Mash7BAC-CreER/RCE:LoxP mouse after induction at E12.5. Scale bar: $50 \mu \mathrm{m}$. C, Voltage responses of cell shown in $\boldsymbol{B}$ to three current step injections $(-200 \mathrm{pA}$, just above threshold, and twice the current for just above threshold). $\boldsymbol{D}$, Phase plot of the voltage response shown in ( to twice the current for just above threshold. Inset illustrates overlaid action potentials; scale bar: $10 \mathrm{mV}, 2 \mathrm{~ms}$.

ulation generated during late stages of embryogenesis (Zhao et al., 2008). Moreover, in contrast to our current findings in hippocampus, considerable evidence indicates a CGE origin of NGCs in the neocortex where nNOS expression is reduced (Butt et al., 2005; Miyoshi et al., 2007) (Miyoshi et al., 2010). Combined with our current findings, these observations suggest that $\mathrm{nNOS}^{-} / \mathrm{NPY}^{+}$NGCs likely arise from CGE progenitors. Using the Mash1BAC-CreER/RCE:LoxP line, we examined the morphology of CGE-derived interneurons located in the s.l.m. after GFP immunolabeling. At each time point tested (E12.5, E14.5, and E16.5), we found $\mathrm{GFP}^{+}$cells exhibiting a neurogliaform like architecture (Fig. 6A) with dendritic arbors that profusely ramified close to the cell body. To ascertain the identity of these cells, we recorded $34 \mathrm{GFP}^{+}$interneurons from animals induced at E12.5 and E16.5. Among these, 16 cells exhibited a LS phenotype similar to the firing profile of NGCs described above (Fig. 6; supplemental Fig. S1, available at www.jneurosci.org as supplemental material). The remaining cells exhibited adapting spiking in response to near threshold stimulation and these did not possess NGC morphologies. Biocytin filling and staining of eight

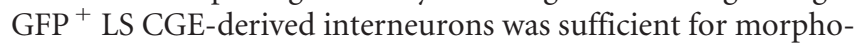
logical classification as NGCs. scPCR analysis of these cells revealed prominent GAD65 (8 out of 8), GAD67 (8 out of 8), GABAAR $\alpha 1$ ( 7 out of 8 ), and NPY ( 8 out of 8 ), but variable nNOS (4 out $\mathrm{f} 8$ ) transcript expression. An example of a CGE-derived LS interneuron fully identified as a NGC is illustrated in Figure 6. These results are consistent with previous studies that have identified NGCs in the GAD65-GFP transgenic line that principally labels CGE-derived cortical interneurons (López-Bendito et al., 2004; Xu and Callaway, 2009). Thus, a subset of immunocytochemically
nNOS $^{-}$NGCs are derived from the CGE and therefore should be considered distinct from nNOS ${ }^{+}$MGE-derived NGCs.

\section{Discussion}

GABAergic neurons expressing $\mathrm{nNOS}$ are one of the largest interneuron populations in the hippocampus (Jinno and Kosaka, 2002; Czéh et al., 2005; Fuentealba et al., 2008b). In this study, lineage analyses based on genetic fate mapping combined with molecular, electrophysiological, and morphological characterization showed that these interneurons derive from both MGE and CGE. Remarkably, our findings reveal that IvCs and nNOS ${ }^{+}$ NGCs have completely overlapping developmental, electrophysiological, morphological, and neurochemical properties, suggesting that these cells constitute a single unique interneuron subtype despite differences in laminar organization. Surprisingly, classically defined NGCs can be subdivided into two groups based on nNOS expression and lineage with $\mathrm{nNOS}^{+}$ NGCs being derived from the MGE and nNOS $^{-}$NGCs arising from CGE progenitors. A schematic diagram summarizing these findings is shown in Figure 7.

\section{Ivy and $\mathrm{nNOS}^{+}$neurogliaform interneurons are generated within the MGE}

IvCs and NGCs have been argued to represent distinct interneuron subtypes (Fuentealba et al., 2008b), despite the rich similarity between these cell types, including coexpression of NPY with nNOS, dense axonal arbors, and slow pyramidal cell inhibition. We found that both of these interneurons exhibit a LS phenotype and fail to express other classical interneuron markers such as PV, SOM, or CR. Our initial characterization based on several electrophysiological and molecular properties is consistent with previous findings in separate $\mathrm{IvC}$ and NGC studies (Price et al., 2005; Szabadics et al., 2007; Fuentealba et al., 2008b), yet failed to reveal any clear distinction between IvCs and NGCs. Thus, we turned to developmental studies to examine whether IvCs and NGCs could be parsed based on lineage profiles. Our fate-mapping analyses revealed that IvCs and the majority of NGCs, the $\mathrm{nNOS}^{+}$cohort, derive from the same progenitor pool in the MGE. Using lineage analysis with an Nkx2-1BAC-Cre driver allele and inducible genetic fate mapping with the Olig2CreER allele combined with GFP reporter lines, we determined that both IvCs and $\mathrm{nNOS}^{+}$NGCs are generated within the MGE. However, Nkx2-1 is also expressed in the preoptic area (POA) (Flames et al., 2007), a region adjacent to the MGE that gives rise to some cortical $\mathrm{NPY}^{+}$interneurons (Gelman et al., 2009). Despite the fact POA-derived hippocampal interneurons remain to be identified, their neocortical homologs lack basic features of IvCs and NGCs such as coexpression of NPY with nNOS and LS behavior (Gelman et al., 2009), making it unlikely that any nNOS ${ }^{+} / \mathrm{GFP}^{+}$cells in the Nkx2-1BAC-Crel $R C E$ :LoxP originate from the POA. Thus, our lineage analysis indicates a common developmental origin for IvCs and NGCs within the MGE. However, given the distinct laminar organiza- 


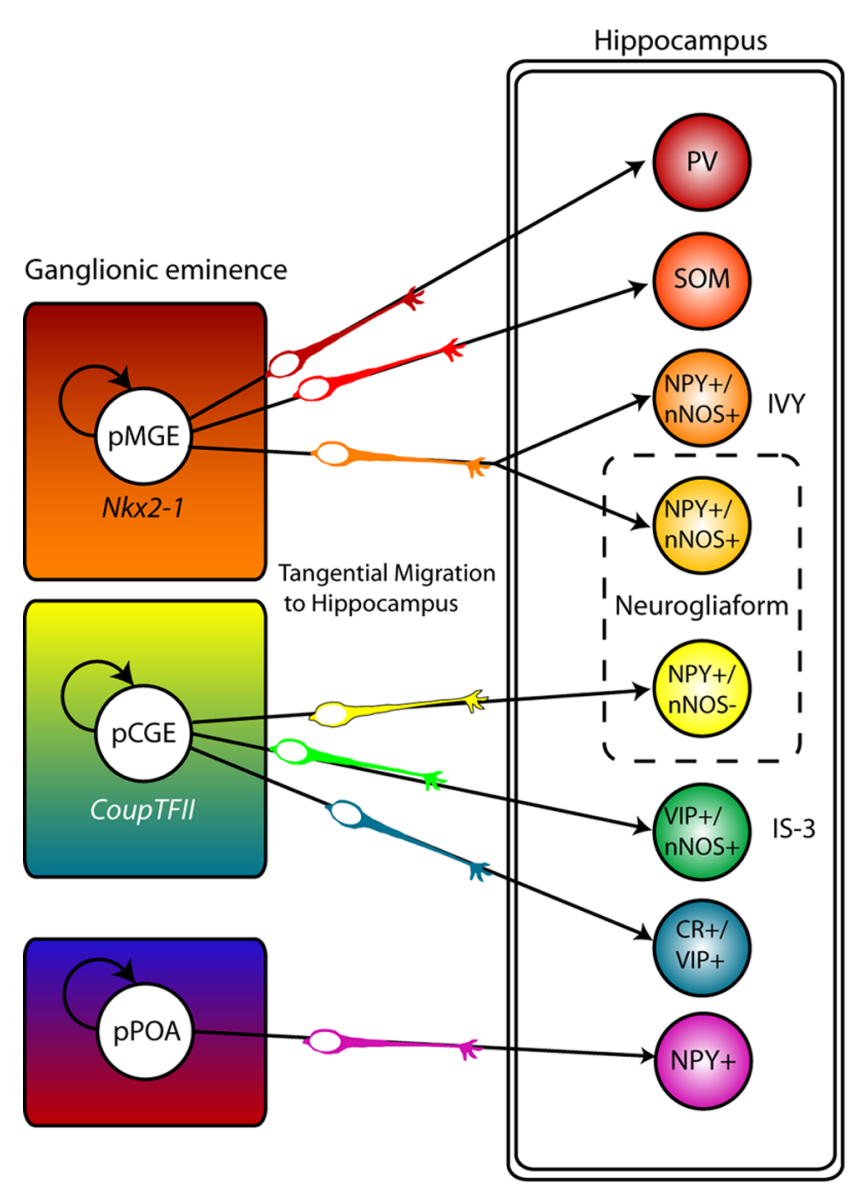

Figure 7. Origin of nNOS ${ }^{+}$and other main hippocampal interneuron subtypes. Schematic diagram summarizing the findings reported in the present study. The scheme is completed based on previous reports using genetic fate mapping for elucidating the sources of hippocampal PV, SOM, NPY, and CR interneurons (Fogarty et al., 2007; Gelman et al., 2009). p, A progenitor stage that does not yet express the denoted subgroup marker. Note that while NPY-expressing interneurons derived from the POA were not specifically examined in the present study, they exhibit a non-late spiking firing pattern and are nNOS-negative (Gelman et al., 2009), thus distinguishing them from MGE/CGE-derived neurogliaform/lvy cells.

tion, and hence synaptic connectivity of IvCs and NGCs, it is possible that both cell types mature under distinct local environmental cues. Moreover, it remains possible that the respective progenitors that give rise to NGCs and IvCs within the MGE are under differential patterning influences that have yet to be elucidated (Xu et al., 2005; Wonders et al., 2008).

\section{Dual origin of $\mathrm{nNOS}^{+}$interneurons}

Several recent studies have determined the embryonic sources of various distinct neocortical interneuron populations, yielding considerable insight into the origins of interneuron diversity (Wonders and Anderson, 2006; Batista-Brito and Fishell, 2009). However, despite the widespread expression of nNOS within GABAergic cells (Jinno and Kosaka, 2002), the developmental origin, specification, and circuit integration properties of $\mathrm{nNOS}^{+}$interneurons have remained elusive as investigation has been hampered by heterogeneous nNOS expression levels (Lee and Jeon, 2005) and perinatal lethality of Nkx2-1-deficient mice (Pleasure et al., 2000). To overcome this latter issue, we used inducible conditional loss of function to examine the role of Nkx2-1 in specifying nNOS $^{+}$interneurons. The longer survival of conditional Nkx2-1 knock-out mice allowed us to investigate the role of $\mathrm{Nkx} 2-1$ in a broader nNOS interneuron population, as we could extend our study to postnatal time points when nNOS is typically upregulated to yield mature expression patterns (Morys et al., 2002). We found that Nkx2-1 deficiency in interneuron precursors results in a large loss of $\mathrm{nNOS}^{+}$interneurons postnatally, consistent with the decrease of cortical nNOS ${ }^{+}$interneurons in embryonic (E19) Nkx2-1 knock-out mice (Anderson et al., 2001). In contrast with $\mathrm{PV}^{+}$interneurons that were almost completely absent in the hippocampus of mutant animals, we observed a small but significant proportion of $\mathrm{nNOS}^{+}$interneurons still present after loss of function at E10.5. Although a fraction of $\mathrm{nNOS}^{+}$interneurons are generated before E10.5, as shown by the temporal fate mapping of MGE-derived interneurons, and thus could have escaped from control of Nkx2-1, most of the remaining $\mathrm{nNOS}^{+}$interneurons in the mutant postnatal hippocampus are located in s.p. Thus, it is likely that the remaining $\mathrm{nNOS}^{+}$interneurons originate from the CGE, as corrobo-

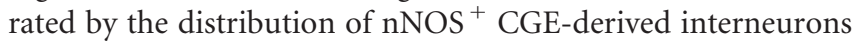
and the bipolar morphology of remaining $\mathrm{nNOS}^{+}$cells in the mutants. These data are also consistent with the results of lineage analysis of MGE-derived interneurons using the Nkx2-1BAC-Cre allele, in which the overlap between GFP and nNOS was weakest in s.p. While it is possible that the remaining $\mathrm{nNOS}^{+}$cells result from respecification of MGE-derived precursors into a CGE-like phenotype (Butt et al., 2008), the most parsimonious explanation is that the majority of $\mathrm{nNOS}^{+}$cells originate from the MGE with a small cohort derived from the CGE.

Consistent with a CGE origin of some $\mathrm{nNOS}^{+}$interneurons, nNOS is expressed in a subset of $\mathrm{CR}^{+}$interneurons (Jinno and Kosaka, 2002). Using transgenic mice that express GFP in CGEderived interneurons, we identified a bipolar NPY-lacking nNOS $^{+}$interneuron population that coexpresses VIP and mainly localizes near the pyramidal layer. The diverse firing properties of these cells are consistent with those of neocortical $\mathrm{VIP}^{+}$interneurons (Porter et al., 1998). In general, the properties of $\mathrm{nNOS}^{+} / \mathrm{VIP}^{+}$neurons are reminiscent of type IS3 cells that are thought to inhibit a subset of $\mathrm{SOM}^{+}$interneurons located in s.o. that project in turn to s.l.m. (Freund and Buzsáki, 1996). Thus, the small cohort of CGE-derived $\mathrm{nNOS}^{+}$interneurons may represent interneuron targeting interneurons, revealing a potential functional segregation between CGE- versus MGEderived nNOS $^{+}$cells. In addition, nNOS could be a useful marker to discriminate IS3 from the two other IS cell subtypes.

\section{Dual origin of neurogliaform interneurons}

Historically, NGCs have been viewed as a functionally homogenous interneuron subtype characterized by the expression of NPY with frequent coexpression of nNOS (Tamás et al., 2003; Price et al., 2005). Provided the NPY-GFP mice used for our initial characterization accurately report the total NGC population, we found that the nNOS ${ }^{+}$subset, hence MGE derived, represents the majority of all hippocampal NGCs with a minor contribution from CGE-derived NGCs. This contrasts with findings in the neocortex in which fate-mapping evidence supports a dominant CGE origin for NGCs (Butt et al., 2005; Miyoshi et al., 2007) (Miyoshi et al., 2010). Interestingly, our hippocampal CGE-derived population of $\mathrm{NGCs}$ is $\mathrm{nNOS}^{-}$, perhaps explaining the reduced level of nNOS in the neocortex (Yan and Garey, 1997; Lee and Jeon, 2005). This striking difference between neocortical and hippocampal NGCs suggests that interneuron precursors could be fated early during embryogenesis to reside in either the hippocampus or neocortex, perhaps reflecting differential sensitivities to specific sorting factors like chemokines (Li et al., 2008; Lopez-Bendito et al., 2008) that promote migration of $\mathrm{nNOS}^{+}$ 
NGC and IvC precursors into the hippocampus instead of stopping to enter the neocortex. Alternatively, these cells may adopt a different fate depending on whether they integrate into the hippocampus or neocortex due to differential expression of morphogenic molecules within these local environments.

We also identified two groups of NGCs that originate from different ganglionic eminences but migrate to the same layer (s.l.m.) and adopt very similar electrophysiological, morphological, and molecular phenotypes. This leads to consideration of whether nNOS ${ }^{+}$and nNOS ${ }^{-}$NGCs subserve different functions within the hippocampus. The opposite vasoactive properties of NO and NPY (Cauli et al., 2004) and the preferential location of NGCs in a blood vessel rich region (L. Tricoire and C. J. McBain, unpublished observations) (Coyle; 1978; Price et al., 2005) suggest that $\mathrm{nNOS}^{+}$NGCs might have a central role in spatially coordinating hippocampal hemodynamics with changes in local circuit activity (Estrada and DeFelipe, 1998). Similarly, dual expression of NPY/nNOS could allow exquisite bidirectional regulation of synaptic transmission (Bacci et al., 2002; Garthwaite,

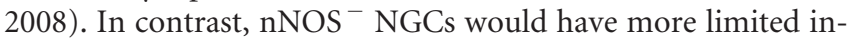
fluence over local hemodynamics and synaptic activity. These differences could be particularly important if the two NGC cohorts exhibit distinct afferent/efferent connectivity.

Despite their distinct origins and differential nNOS expression, CGE- and MGE-derived NGCs ultimately adopt indistinguishable morphological and electrophysiological properties with similar molecular profiles. This leads one to question the role of genetic specification versus local environment in controlling the integration and maturation of GABAergic neurons in the hippocampal network. For example, NPY expression is dependent upon neuronal activity (Marty, 2000) and its level in both NGC cohorts may be driven by the shared excitatory inputs from CA3 and entorhinal cortex (Price et al., 2005). By analogy, the morphological and electrophysiological similarity between the two NGC groups could reflect sensitivity to a common morphogen present within s.l.m. In contrast, nNOS expression could be largely predetermined by genetic programming at the embryonic progenitor level, as the majority of $\mathrm{nNOS}^{+}$interneurons belong to the same embryonic lineage. Such nature versus nurture influences upon the ultimate fate of postmigratory interneurons remain largely unexplored but may contribute to cortical interneuron diversity.

In conclusion, we used a multiparametric approach to examine the diversity of hippocampal $\mathrm{nNOS}^{+}$interneurons with particular emphasis on determining whether IvCs and NGCs can be distinguished upon combined electrophysiological, molecular, and developmental criteria. However, our findings do not provide evidence that these two groups can be parsed based on these parameters. Nonetheless, we cannot rule out the possibility that these two interneuron subpopulations perform distinct functions during network activity that would be dictated by their respective laminar organization and connectivity (Somogyi et al., 1998). Indeed, another classification scheme based on interneuron firing properties during discrete network activity patterns (Klausberger and Somogyi, 2008) may find temporally distinct contributions of IvCs and NGCs to circuit oscillations (Fuentealba et al., 2008b).

\section{References}

Anderson S, Mione M, Yun K, Rubenstein JL (1999) Differential origins of neocortical projection and local circuit neurons: role of Dlx genes in neocortical interneuronogenesis. Cereb Cortex 9:646-654.

Anderson SA, Marín O, Horn C, Jennings K, Rubenstein JL (2001) Distinct cortical migrations from the medial and lateral ganglionic eminences. Development 128:353-363.
Bacci A, Huguenard JR, Prince DA (2002) Differential modulation of synaptic transmission by neuropeptide $\mathrm{Y}$ in rat neocortical neurons. Proc Natl Acad Sci U S A 99:17125-17130.

Batista-Brito R, Fishell G (2009) The developmental integration of cortical interneurons into a functional network. Curr Top Dev Biol 87:81-118.

Batista-Brito R, Machold R, Klein C, Fishell G (2008) Gene expression in cortical interneuron precursors is prescient of their mature function. Cereb Cortex 18:2306-2317.

Battiste J, Helms AW, Kim EJ, Savage TK, Lagace DC, Mandyam CD, Eisch AJ, Miyoshi G, Johnson JE (2007) Ascll defines sequentially generated lineage-restricted neuronal and oligodendrocyte precursor cells in the spinal cord. Development 134:285-293.

Butt SJ, Fuccillo M, Nery S, Noctor S, Kriegstein A, Corbin JG, Fishell G (2005) The temporal and spatial origins of cortical interneurons predict their physiological subtype. Neuron 48:591-604.

Butt SJ, Sousa VH, Fuccillo MV, Hjerling-Leffler J, Miyoshi G, Kimura S, Fishell G (2008) The requirement of Nkx2-1 in the temporal specification of cortical interneuron subtypes. Neuron 59:722-732.

Cauli B, Audinat E, Lambolez B, Angulo MC, Ropert N, Tsuzuki K, Hestrin S, Rossier J (1997) Molecular and physiological diversity of cortical nonpyramidal cells. J Neurosci 17:3894-3906.

Cauli B, Tong XK, Rancillac A, Serluca N, Lambolez B, Rossier J, Hamel E (2004) Cortical GABA interneurons in neurovascular coupling: relays for subcortical vasoactive pathways. J Neurosci 24:8940-8949.

Cossart R, Bernard C, Ben-Ari Y (2005) Multiple facets of GABAergic neurons and synapses: multiple fates of GABA signalling in epilepsies. Trends Neurosci 28:108-115.

Coyle P (1978) Spatial features of the rat hippocampal vascular system. Exp Neurol 58:549-561.

Czéh B, Hajnal A, Seress L (2005) NADPH-diaphorase positive neurons of the rat hippocampal formation: regional distribution, total number and colocalization with calcium binding proteins. Prague Med Rep 106:261-274.

Estrada C, DeFelipe J (1998) Nitric oxide-producing neurons in the neocortex: morphological and functional relationship with intraparenchymal microvasculature. Cereb Cortex 8:193-203.

Flames N, Pla R, Gelman DM, Rubenstein JL, Puelles L, Marín O (2007) Delineation of multiple subpallial progenitor domains by the combinatorial expression of transcriptional codes. J Neurosci 27:9682-9695.

Fogarty M, Grist M, Gelman D, Marín O, Pachnis V, Kessaris N (2007) Spatial genetic patterning of the embryonic neuroepithelium generates GABAergic interneuron diversity in the adult cortex. J Neurosci 27:10935-10946.

Freund TF, Buzsáki G (1996) Interneurons of the hippocampus. Hippocampus 6:347-470.

Fuentealba P, Tomioka R, Dalezios Y, Márton LF, Studer M, Rockland K, Klausberger T, Somogyi P (2008a) Rhythmically active enkephalin-expressing GABAergic cells in the CAl area of the hippocampus project to the subiculum and preferentially innervate interneurons. J Neurosci 28:10017-10022.

Fuentealba P, Begum R, Capogna M, Jinno S, Márton LF, Csicsvari J, Thomson A, Somogyi P, Klausberger T (2008b) Ivy cells: a population of nitric-oxideproducing, slow-spiking GABAergic neurons and their involvement in hippocampal network activity. Neuron 57:917-929.

Garthwaite J (2008) Concepts of neural nitric oxide-mediated transmission. Eur J Neurosci 27:2783-2802.

Gelman DM, Martini FJ, Nóbrega-Pereira S, Pierani A, Kessaris N, Marín O (2009) The embryonic preoptic area is a novel source of cortical GABAergic interneurons. J Neurosci 29:9380-9389.

Guillemot F, Lo LC, Johnson JE, Auerbach A, Anderson DJ, Joyner AL (1993) Mammalian achaete-scute homolog 1 is required for the early development of olfactory and autonomic neurons. Cell 75:463-476.

Hanashima C, Shen L, Li SC, Lai E (2002) Brain factor-1 controls the proliferation and differentiation of neocortical progenitor cells through independent mechanisms. J Neurosci 22:6526-6536.

Jinno S, Kosaka T (2002) Patterns of expression of calcium binding proteins and neuronal nitric oxide synthase in different populations of hippocampal GABAergic neurons in mice. J Comp Neurol 449:1-25.

Joyner AL, Zervas M (2006) Genetic inducible fate mapping in mouse: establishing genetic lineages and defining genetic neuroanatomy in the nervous system. Dev Dyn 235:2376-2385.

Kanatani S, Yozu M, Tabata H, Nakajima K (2008) COUP-TFII is preferentially expressed in the caudal ganglionic eminence and is involved in the caudal migratory stream. J Neurosci 28:13582-13591.

Karagiannis A, Gallopin T, Dávid C, Battaglia D, Geoffroy H, Rossier J, 
Hillman EM, Staiger JF, Cauli B (2009) Classification of NPY-expressing neocortical interneurons. J Neurosci 29:3642-3659.

Kawaguchi Y (1995) Physiological subgroups of nonpyramidal cells with specific morphological characteristics in layer II/III of rat frontal cortex. J Neurosci 15:2638-2655.

Klausberger T, Somogyi P (2008) Neuronal diversity and temporal dynamics: the unity of hippocampal circuit operations. Science 321:53-57.

Kusakabe T, Kawaguchi A, Hoshi N, Kawaguchi R, Hoshi S, Kimura S (2006) Thyroid-specific enhancer-binding protein/NKX2.1 is required for the maintenance of ordered architecture and function of the differentiated thyroid. Mol Endocrinol 20:1796-1809.

Lambolez B, Audinat E, Bochet P, Crépel F, Rossier J (1992) AMPA receptor subunits expressed by single Purkinje cells. Neuron 9:247-258.

Lavdas AA, Grigoriou M, Pachnis V, Parnavelas JG (1999) The medial ganglionic eminence gives rise to a population of early neurons in the developing cerebral cortex. J Neurosci 19:7881-7888.

Lee JE, Jeon CJ (2005) Immunocytochemical localization of nitric oxide synthase-containing neurons in mouse and rabbit visual cortex and colocalization with calcium-binding proteins. Mol Cells 19:408-417.

Levitt P, Eagleson KL, Powell EM (2004) Regulation of neocortical interneuron development and the implications for neurodevelopmental disorders. Trends Neurosci 27:400-406.

Lewis DA, Hashimoto T, Volk DW (2005) Cortical inhibitory neurons and schizophrenia. Nat Rev Neurosci 6:312-324.

Li G, Adesnik H, Li J, Long J, Nicoll RA, Rubenstein JL, Pleasure SJ (2008) Regional distribution of cortical interneurons and development of inhibitory tone are regulated by Cxcl12/Cxcr4 signaling. J Neurosci 28:1085- 1098.

Liodis P, Denaxa M, Grigoriou M, Akufo-Addo C, Yanagawa Y, Pachnis V (2007) Lhx6 activity is required for the normal migration and specification of cortical interneuron subtypes. J Neurosci 27:3078-3089.

López-Bendito G, Sturgess K, Erdélyi F, Szabó G, Molnár Z, Paulsen O (2004) Preferential origin and layer destination of GAD65-GFP cortical interneurons. Cereb Cortex 14:1122-1133.

López-Bendito G, Sánchez-Alcañiz JA, Pla R, Borrell V, Picó E, Valdeolmillos M, Marín O (2008) Chemokine signaling controls intracortical migration and final distribution of GABAergic interneurons. J Neurosci 28:1613-1624.

Lu QR, Sun T, Zhu Z, Ma N, Garcia M, Stiles CD, Rowitch DH (2002) Common developmental requirement for Olig function indicates a motor neuron/oligodendrocyte connection. Cell 109:75-86.

Marty S (2000) Differences in the regulation of neuropeptide Y, somatostatin and parvalbumin levels in hippocampal interneurons by neuronal activity and BDNF. Prog Brain Res 128:193-202.

Milgram SL, Chang EY, Mains RE (1996) Processing and routing of a membrane-anchored form of proneuropeptide Y. Mol Endocrinol 10:837-846.

Miyoshi G, Butt SJ, Takebayashi H, Fishell G (2007) Physiologically distinct temporal cohorts of cortical interneurons arise from telencephalic Olig2expressing precursors. J Neurosci 27:7786-7798.

Miyoshi G, Hjerling-Leffler J, Karayannis T, Sousa VH, Butt SJB, Battiste J, Johnson JE, Machold RP, Fishell G (2010) Genetic fate mapping reveals that the caudal ganglionic eminence produces a large and diverse population of superficial cortical interneurons. J Neurosci 30:1582-1594.

Moryś JM, Kowiański P, Moryś J (2002) Distribution of nitric oxide synthase and neuropeptide $\mathrm{Y}$ neurones during the development of the hippocampal formation in the rat. Folia Morphol (Warsz) 61:221-232.

Nery S, Fishell G, Corbin JG (2002) The caudal ganglionic eminence is a source of distinct cortical and subcortical cell populations. Nat Neurosci 5:1279-1287.

Novak A, Guo C, Yang W, Nagy A, Lobe CG (2000) Z/EG, a double reporter mouse line that expresses enhanced green fluorescent protein upon Cremediated excision. Genesis 28:147-155.

Pinto S, Roseberry AG, Liu H, Diano S, Shanabrough M, Cai X, Friedman JM, Horvath TL (2004) Rapid rewiring of arcuate nucleus feeding circuits by leptin. Science 304:110-115.

Pleasure SJ, Anderson S, Hevner R, Bagri A, Marin O, Lowenstein DH, Rubenstein JL (2000) Cell migration from the ganglionic eminences is required for the development of hippocampal GABAergic interneurons. Neuron 28:727-740.

Porter JT, Cauli B, Staiger JF, Lambolez B, Rossier J, Audinat E (1998) Properties of bipolar VIPergic interneurons and their excitation by pyramidal neurons in the rat neocortex. Eur J Neurosci 10:3617-3628.
Price CJ, Cauli B, Kovacs ER, Kulik A, Lambolez B, Shigemoto R, Capogna M (2005) Neurogliaform neurons form a novel inhibitory network in the hippocampal CA1 area. J Neurosci 25:6775-6786.

Somogyi P, Klausberger T (2005) Defined types of cortical interneurone structure space and spike timing in the hippocampus. J Physiol 562:9-26.

Somogyi P, Tamás G, Lujan R, Buhl EH (1998) Salient features of synaptic organisation in the cerebral cortex. Brain Res Brain Res Rev 26:113-135.

Soriano E, Del Río JA, Martínez A, Supèr H (1994) Organization of the embryonic and early postnatal murine hippocampus. I. Immunocytochemical characterization of neuronal populations in the subplate and marginal zone. J Comp Neurol 342:571-595.

Sousa VH, Miyoshi G, Hjerling-Leffler J, Karayannis T, Fishell G (2009) Characterization of $\mathrm{Nkx6}$-2-derived neocortical interneuron lineages. Cereb Cortex 19 [Suppl 1]:i1-i10.

Stuart G, Häusser M (1994) Initiation and spread of sodium action potentials in cerebellar Purkinje cells. Neuron 13:703-712.

Sussel L, Marin O, Kimura S, Rubenstein JL (1999) Loss of Nkx2.1 homeobox gene function results in a ventral to dorsal molecular respecification within the basal telencephalon: evidence for a transformation of the pallidum into the striatum. Development 126:3359-3370.

Szabadics J, Soltesz I (2009) Functional specificity of mossy fiber innervation of GABAergic cells in the hippocampus. J Neurosci 29:4239-4251.

Szabadics J, Tamás G, Soltesz I (2007) Different transmitter transients underlie presynaptic cell type specificity of GABAA,slow and GABAA,fast. Proc Natl Acad Sci U S A 104:14831-14836.

Takebayashi H, Nabeshima Y, Yoshida S, Chisaka O, Ikenaka K, Nabeshima Y (2002) The basic helix-loop-helix factor olig2 is essential for the development of motoneuron and oligodendrocyte lineages. Curr Biol 12:1157-1163.

Tamás G, Lorincz A, Simon A, Szabadics J (2003) Identified sources and targets of slow inhibition in the neocortex. Science 299:1902-1905.

van den Pol AN, Yao Y, Fu LY, Foo K, Huang H, Coppari R, Lowell BB, Broberger C (2009) Neuromedin B and gastrin-releasing peptide excite arcuate nucleus neuropeptide $\mathrm{Y}$ neurons in a novel transgenic mouse expressing strong Renilla green fluorescent protein in NPY neurons. J Neurosci 29:4622-4639.

Vida I, Halasy K, Szinyei C, Somogyi P, Buhl EH (1998) Unitary IPSPs evoked by interneurons at the stratum radiatum-stratum lacunosummoleculare border in the CA1 area of the rat hippocampus in vitro. J Physiol 506:755-773.

Wichterle H, Turnbull DH, Nery S, Fishell G, Alvarez-Buylla A (2001) In utero fate mapping reveals distinct migratory pathways and fates of neurons born in the mammalian basal forebrain. Development 128:3759-3771.

Willi-Monnerat S, Migliavacca E, Surdez D, Delorenzi M, Luthi-Carter R, Terskikh AV (2008) Comprehensive spatiotemporal transcriptomic analyses of the ganglionic eminences demonstrate the uniqueness of its caudal subdivision. Mol Cell Neurosci 37:845-856.

Wonders CP, Anderson SA (2006) The origin and specification of cortical interneurons. Nat Rev Neurosci 7:687-696.

Wonders CP, Taylor L, Welagen J, Mbata IC, Xiang JZ, Anderson SA (2008) A spatial bias for the origins of interneuron subgroups within the medial ganglionic eminence. Dev Biol 314:127-136.

Xu Q, Cobos I, De La Cruz E, Rubenstein JL, Anderson SA (2004) Origins of cortical interneuron subtypes. J Neurosci 24:2612-2622.

Xu Q, Wonders CP, Anderson SA (2005) Sonic hedgehog maintains the identity of cortical interneuron progenitors in the ventral telencephalon. Development 132:4987-4998.

Xu Q, Tam M, Anderson SA (2008) Fate mapping Nkx2.1-lineage cells in the mouse telencephalon. J Comp Neurol 506:16-29.

Xu X, Callaway EM (2009) Laminar specificity of functional input to distinct types of inhibitory cortical neurons. J Neurosci 29:70-85.

Yan XX, Garey LJ (1997) Morphological diversity of nitric oxide synthesising neurons in mammalian cerebral cortex. J Hirnforsch 38:165-172.

Zhao Y, Flandin P, Long JE, Cuesta MD, Westphal H, Rubenstein JL (2008) Distinct molecular pathways for development of telencephalic interneuron subtypes revealed through analysis of Lhx6 mutants. J Comp Neurol 510:79-99.

Zsiros V, Maccaferri G (2005) Electrical coupling between interneurons with different excitable properties in the stratum lacunosum-moleculare of the juvenile CA1 rat hippocampus. J Neurosci 25:8686-8695. 